\title{
APLICACIÓN DE LA TECNOLOGÍA LÁSER (LIDAR) EN LA ZONIFICACIÓN DE ÁREAS DE INUNDACIÓN DEL RÍO REHUE EN LA CIUDAD DE ANGOL
}

\section{APPLICATION OF LASER TECHNOLOGY (LIDAR) IN THE ZONING OF FLOOD AREAS OF THE REHUE RIVER IN THE CITY OF ANGOL}

\author{
Sr. Alejandro Rodríguez Parra ${ }^{1}$ \\ Sr. Gonzalo Ortega Candia²
}

\begin{abstract}
RESUMEN
El avance tecnológico en diferentes disciplinas de la geomática ha producido mejoras sustanciales en la precisión de los datos obtenidos de la superficie de la Tierra, esto gracias a los instrumentos especializados en la adquisición de dichos datos o a los softwares utilizados para su procesamiento. La alta precisión del sensor láser (LIDAR) en la captura de datos del relieve y los elementos sobre la superficie de este, han aportado mayor fiabilidad a los resultados obtenidos a través de modelos utilizados para el cálculo de parámetros y estimación de variables, tanto en estudios de ingeniería como en otras disciplinas. La tecnología LIDAR ha sido aplicada en este estudio para determinar las áreas de inundación del río Rehue en la ciudad de Angol, con el fin de que la información obtenida pueda servir como insumo en la gestión de los Instrumentos de Planificación Territorial. Para efectos de este estudio, también se recolectaron y analizaron datos relativos a la geomorfología, hidrología, suelo y clima, los cuales se comportaron como las principales variables para la obtención de los resultados, siendo estas utilizadas en el modelamiento en los respectivos softwares ArcGis 10.5, HecRas 5.0.5 y HecGeoRas. Finalmente, los resultados de este estudio se presentan tanto en tablas y cartografía temática, así como también en ortofotos para una mayor apreciación de éstos.
\end{abstract}

Palabras Claves: LIDAR, Inundación, Variables, Simulación y Zonificación.

\begin{abstract}
The technological advance in different disciplines of geomatics has produced substantial improvements in the accuracy of the data obtained from the Earth's surface, this thanks to the specialized instruments in the acquisition of said data or to the software used for its processing. The high precision of the laser sensor (LIDAR) in the capture of data of the relief and the elements on the surface of this, have contributed greater reliability to the results obtained through models used for the calculation of parameters and estimation of variables, both in engineering studies as in other disciplines. The LIDAR technology has been applied in this study to determine the flood areas of the Rehue River in the city of Angol, so that the information obtained can serve as input in the management of the Territorial Planning Instruments. For the purposes of this study, data related to geomorphology, hydrology, soil and climate were also collected and analyzed, which behaved as the main variables for obtaining the results, being used in modeling in the respective ArcGis 10.5 software, HecRas 5.0.5 and HecGeoRas. Finally, the results of this study are presented both in tables and thematic cartography, as well as in orthophotos for a greater appreciation of these.
\end{abstract}

Keywords: LIDAR, Flood, Variables, Simulation and Zoning.

\footnotetext{
1 Escuela Ciencias de la Tierra, Universidad Bernardo O’Higgins, alerodriguezparra30@gmail.com

2 Escuela Ciencias de la Tierra, Universidad Bernardo O’Higgins, ortega.gonzalo@gmail.com
}

Fecha de recepción: 30 de agosto de 2019

Fecha de aprobación: 12 de diciembre de 2019 


\section{INTRODUCCIÓN}

Como se ha evidenciado en el último tiempo, no han sido pocas las localidades del territorio nacional las que se han visto afectadas por fenómenos naturales y otros producidos 0 desencadenados por actividades antrópicas, afectando así, a miles de personas en distintas latitudes y épocas.

Junto con ello, la expansión urbana en las últimas décadas, se ha visto acelerada por la migración de los pobladores de zonas rurales o comunas con menor densidad de población, hacia las ciudades o urbes con una alta concentración de esta. Los factores que condicionan dicha actividad son muchos. Tal aceleración, ha producido un crecimiento informal en muchas ocasiones (Paradoja de la Planificación Urbana en Chile, 1995).

Existe una relación directa entre los enunciados de los párrafos anteriores, y es en este contexto donde aparece la planificación urbana (Instrumentos de Planificación Territorial, IPT), herramienta creada para orientar y regular el crecimiento y desarrollo de los territorios bajo una jurisdicción (MINVU, 2018). Un instrumento que, a ojos de los expertos, ha sido cuestionado por su relativa efectividad dado que algunos fenómenos naturales han ocurrido en zonas no aptas para la construcción de viviendas.

Dado este escenario, y con el objetivo de disminuir los riesgos a los cuales se enfrenta la población, resulta necesario que las autoridades locales cuenten con mayores antecedentes al momento de tomar decisiones, basadas en estudios recientes de ingeniería y otras disciplinas, a fin de evitar o disminuir la vulnerabilidad latente propia de toda sociedad.

En el marco de análisis de esta situación, se dio origen al presente trabajo, el cual centró su atención en el estudio de la zonificación de áreas de inundación, utilizando datos LIDAR, para la representación del relieve y los softwares HecRas y HecGeoRas (ArcGis).

La idea apunta a simular el efecto de crecida del río Rehue, localizado en la ciudad de Angol, en la IX Región de la Araucanía, Chile.

Como se mencionó, el avance tecnológico ha producido una mejora sustancial en la precisión de los datos obtenidos para realizar estudios de ingeniería.

La tecnología láser (LIDAR), pertenece a este campo, por lo que se han aprovechado sus capacidades, como son la precisión, concentración, volumen y rapidez en la captura de datos, para la materialización de este trabajo.

Para determinar las áreas de inundación, objetivo principal del estudio, se procedió con la adquisición, procesamiento y clasificación de datos (láser) en el software Microstation V8, para obtener un Modelo Digital del Terreno y Modelo Digital de Superficie de mayor precisión. Con el modelo digital se determinaron las propiedades topográficas del terreno (pendiente, orientación, profundidad y elevación).

Posteriormente, con información de hidrología, geomorfología, suelo y los parámetros propios del cauce del río (dirección, profundidad, bordes, caudal), los que se utilizaron para generar el modelamiento de inundación en los softwares HecGeoRas (ArcGis 10.5) y HecRas 5.0.5.

Los resultados fueron representados en tablas y cartografía temática, incluyendo también imágenes en 3D.

\section{ÁREA DE ESTUDIO Y METODOLOGÍA}

El curso del río Rehue inserto en el área urbana, cruza de suroeste a norte en un tramo de $4,5 \mathrm{~km}$ aproximadamente la ciudad de Angol (Figura 1), formando parte de la cuenca de Río Bueno (EducarChile(s.f.). Ríos de Chile, 2018). La ciudad de Angol cuenta con una población de 52.262 habitantes según Censo de 2017 (INE, 2017), de los cuales 48.911 residen en el área urbana y 3.351 en el entorno rural. En lo que respecta a las viviendas, las cifras alcanzan las 16.855 casas y 232 departamentos en edificios para el sector urbano (INE, 2017).

El río Rehue, objeto de estudio, se comporta como una barrera natural al dividir a la ciudad en tres fracciones, y en concordancia con ello, es utilizado como límite para la división de algunos distritos censales de la comuna. Como se muestra (Figura 2), 5 son los distritos censales que se encuentran en el área de interés.

Es importante considerar la estrecha relación existente entre los distritos censales y el curso del río. El primero, porque proporciona información de los índices de vulnerabilidad junto con la demografía (carácter cualitativo y cuantitativo), los que permiten valorar los aspectos sociales, mientras que el segundo indica las áreas de zonificación de peligro de inundación, ambos factores primordiales en la ecuación para la determinación de riesgo ante una catástrofe o emergencia. 


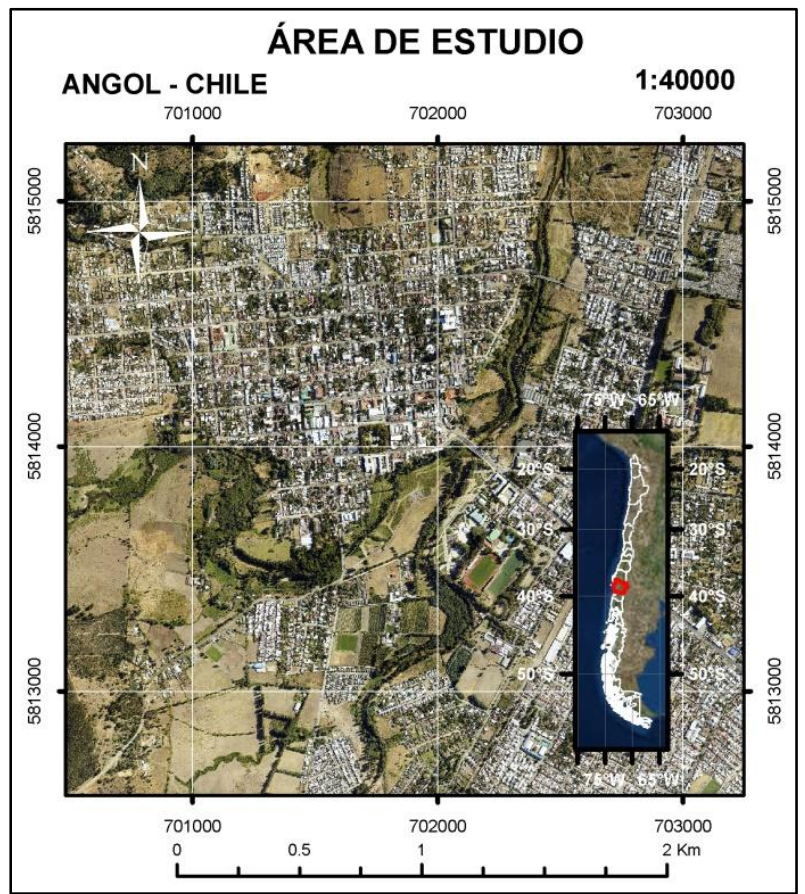

Figura 1. Área de estudio. Fuente: Elaboración propia. Imagen obtenida de Google Earth, 2018

La información entregada por los censos de las últimas décadas, anuncian que el crecimiento entre los años 1993 y 2012, ha experimentado un aumento de la superficie urbana de 391,54 a 866 hectáreas, de las cuales 107 de ellas han sido destinadas para la construcción de viviendas sociales. Los distritos censales que han acogido mayormente este tipo de construcción son el distrito Estación con 2.313 y el distrito Regimiento con 886 viviendas de un total de 3.637 (Verga Erices, y otros, 2013). Lo anterior debido a que hacia el año 1992, ambos distritos contaban con un mayor espacio de suelo disponible para la construcción.

Se analizará en la discusión la importancia de estos antecedentes.

\section{PROCEDIMIENTOS}

En el contexto de tener enfoques desde el punto de vista de la ingeniería y otro de la geografía, el estudio se basa en método analítico ${ }^{3}$ (Lopera Echavarría, y otros, 2010), en el cual se realizaron

3 Es un camino para llegar a un resultado mediante la descomposición de un fenómeno en sus elementos constitutivos (Lopera Echavarría, y otros, 2010). observaciones y registro de cada una de las variables en cada etapa descrita en el estudio.

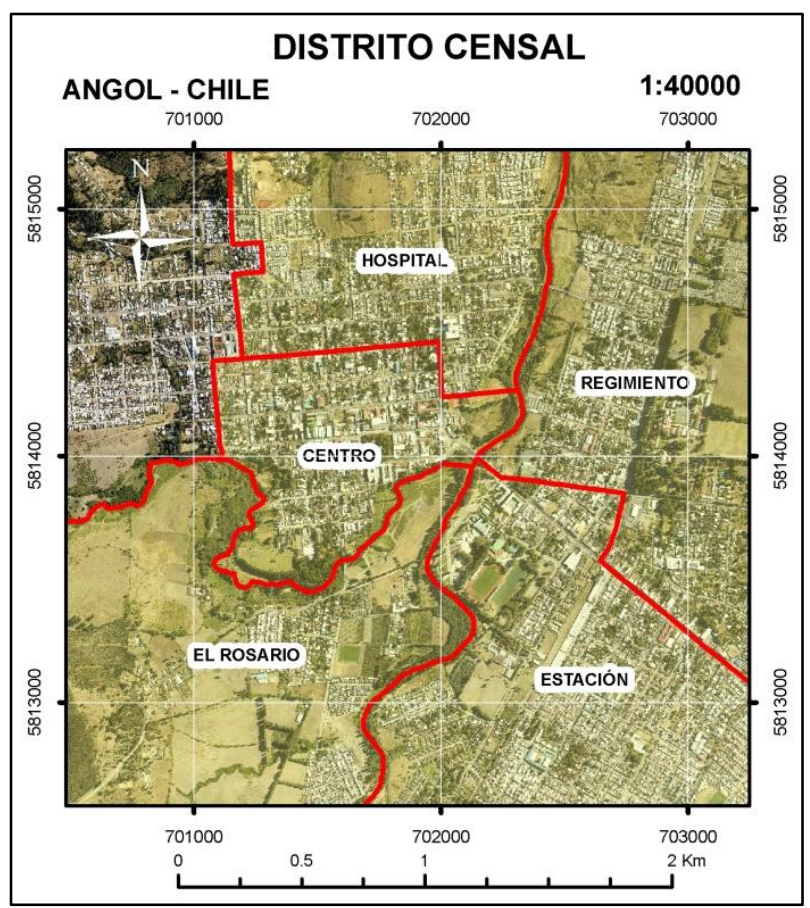

Figura 2. Distritos censales. Fuente: Elaboración propia. Datos: obtenidos de INE, 2018

Para las mediciones se considera obtener datos cuantitativos, los cuales proporcionan información numérica y medible para realizar la modelación de la zonificación de las áreas de inundación en los softwares. Los datos cualitativos, asistirán en la interpretación de los datos cuantitativos alcanzados en la modelación. La modelación se aplicó al MDS con los parámetros propios del río para la obtención de la zonificación.

Se vieron tres fases en la materialización del estudio: 1. Fase de tratamiento de Datos, 2. Modelación sobre la superficie MDS y 3. Integración de datos geográficos. La primera orientada a la descripción de los procedimientos y métodos utilizados en Geomensura para la obtención, diseminación, análisis, clasificación y representación de la información del relieve del área de interés.

La segunda dirigida a la puesta en marcha del modelo en la generación y determinación de las áreas de inundación, para su posterior 
representación de la distribución espacial de la información (cuantitativa y cualitativa), generando cartografía temática de las propiedades del relieve y de las zonas de vulnerabilidad de los distritos censales del área de interés.

En la tercera fase se produce la concatenación de las dos fases anteriores a través de la implementación de un SIG abreviado en el cual se imbrican los resultados.

Fase de tratamiento de datos

LIDAR (por su acrónimo en inglés, Light Detection and Ranging), es un sensor activo, el que, mediante la emisión de pulsos en la longitud del infrarrojo cercano, detecta la radiancia reflejada por los objetos en terreno y calcula el tiempo de su emisión hasta su retorno al sensor.

El sistema está compuesto por 5 subsistemas (Figura 3). La plataforma o medio en el cual se encuentra el sensor, puede ser un avión, helicóptero o un vehículo en el caso de ser terrestre.

Es a través del ALS (Escáner Láser Aerotransportado) que se emiten los pulsos (IRC) y se puede determinar la distancia entre el sensor y el terreno u objeto en el cual reflecte la señal.

EI INS (Sistema de Navegación Inercial), es un dispositivo que orienta la plataforma tomando como referencia la posición de la antena GPS (Global Position System), entregando información respecto a los giros, trayectoria y aceleración de la plataforma.

El GPS Diferencial, está compuesto por el GPS de la plataforma y uno o más GPS en terreno (Apoyo terrestre), se obtiene la posición precisa de la plataforma (coordenadas $x, y, z$ ), lo que permite determinar las coordenadas de los datos capturados.

El último y opcional, es la Cámara de viso digital, que permitirá contar con una imagen de la zona de la cual se obtuvieron los datos (línea de vuelo), para su mejor interpretación y de apoyo cartográfico.

Los datos utilizados fueron obtenidos con un dispositivo Optech 3100 y una cámara fotográfica Rollei $60 \mathrm{mp}$. Los pulsos emitidos tuvieron un intervalo de $70 \mathrm{Khz}$ a una altura de vuelo de $800 \mathrm{~m}$ agl (About ground lavel o Sobre el Nivel del Suelo en español) y a una velocidad de vuelo de $64,8 \mathrm{kn}$ $(120 \mathrm{Km} / \mathrm{h})$.

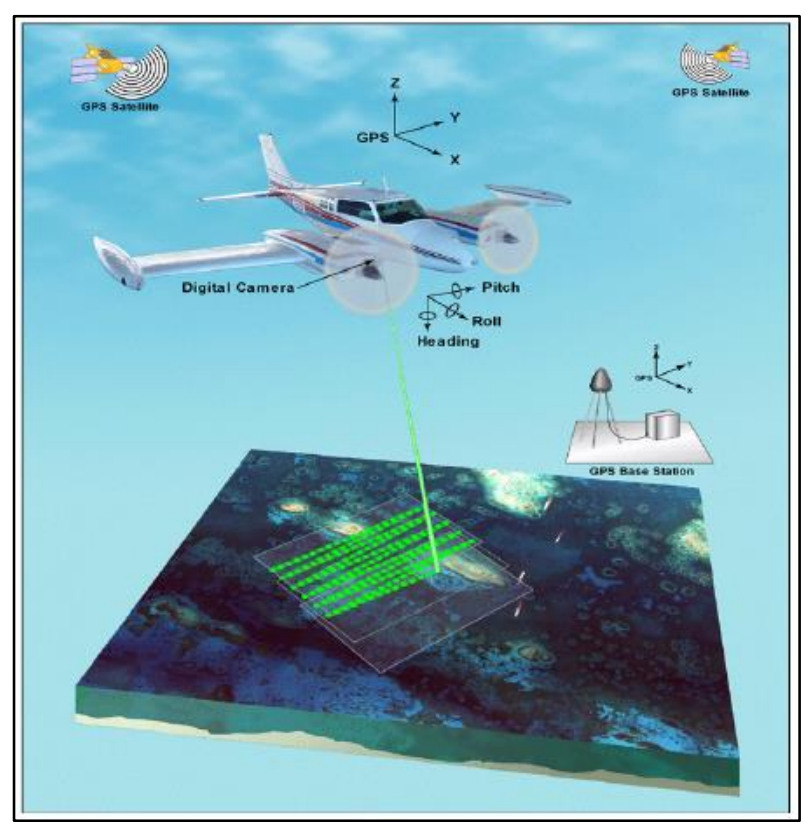

Figura 3. Subsistemas LiDAR. Fuente: (Arellano Sánchez, y otros, s.f.)

Los datos láser obtenidos por la plataforma tienen una referencia elipsoidal (WGS 84, Sistema Geodésico Mundial de 1984, en español), al utilizar GPS, a los que se le calcula su altitud ortométrica. El Huso utilizado es el $18 \mathrm{H}$ (Sur) de la proyección UTM. La precisión planimétrica y altimétrica alcanzan los $\pm 10 \mathrm{~cm}$.

El formato LAS, propio del sistema LIDAR, es compatible con el software MicroStation V8 (familia CAD), y del cual se utilizaron sus módulos para el procesamiento de los datos en el presente proyecto. TerraScan en un módulo dedicado a procesar nubes de punto de escaneo láser. Terramodeler es una aplicación de modelado de terreno construido sobre MicroStation, permitiendo la creación modelados triangulares de suelo, creación de capas de suelo y superficies de diseño y TerraPhoto el cual se utiliza ampliamente para la producción de imágenes ortorrectificadas a partir de imágenes aerotransportadas, útil en la interpretación al momento de la manipulación de los datos (MicroStation $\AA$, MDL ${ }^{\circledR}$ y MicroStation estilizados "M", marcas registradas de Bentley Systems, 2016).

Dentro de las capacidades del sistema LIDAR, destaca el hecho que puede capturar gran cantidad de datos en poco tiempo, aunque el volumen de la información que captura (nube de puntos), dificulte 
la manipulación y tratamiento de los datos. Para resolver este problema, se utilizó la herramienta Block Boundaries (Límites de bloque), del módulo TerraScan, que permite desarrollar una estrategia de trabajo para el tratamiento de puntos, optimizando de esta manera los recursos.

En el área de estudio se utilizaron 10 Límites de Bloque (Figura 4), cada uno de ellos con dimensiones de $1.500 \mathrm{~m}$ este-oeste y $1.250 \mathrm{~m}$ norte-sur y un área de 187,5 ha $\left(1.875 .000 \mathrm{~m}^{2}\right)$.

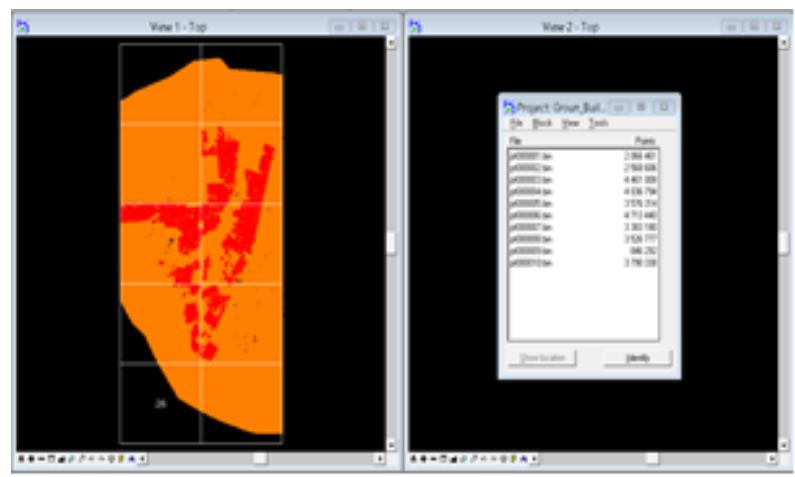

Figura 4. Límites de Bloque. (Vista en MicroStation V8)

Como el sistema láser (empleado en este estudio), tiene la capacidad de captar hasta 4 reflejos o retornos ${ }^{4}$ por cada pulso emitido, pero no es capaz de discernir o diseminar el tipo de entidad de la cual proviene éste, se procedió con la clasificación de los datos. A través del módulo se crearon dos categorías, suelo y edificación, lo que permite una segregación de datos y poder generar un MDT y un MDS respectivamente (Figura 5).

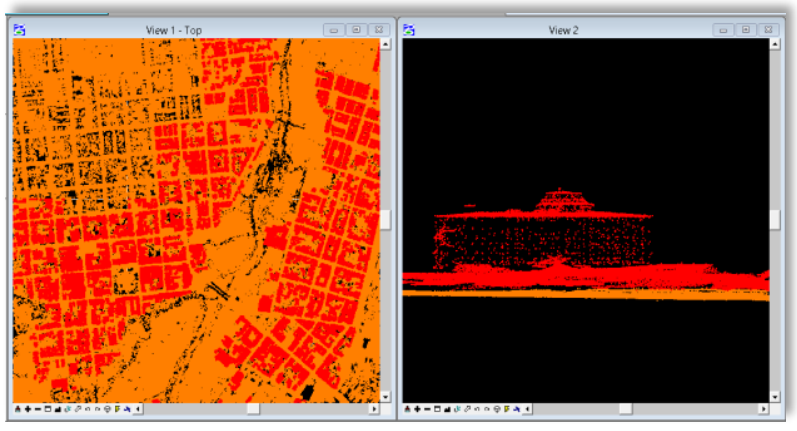

Figura 5. Vista de planta y perfil de puntos de suelo y construcción- (Puntos anaranjados (suelo) y rojos (construcción)).

\footnotetext{
${ }^{4}$ Efecto físico que consiste en captar el reflejo de un haz de
} luz IRC emitido por el sensor.
Este procedimiento adquiere gran importancia, ya que es aquí cuando se produce la independencia entre las entidades (filtrado y eliminación del ruido) (Aplicaciones de la teledetección láser (LIDAR) en la caracterización y gestión del medio fluvial, 2006), para lo cual se debe tener especial cuidado en discriminar de manera correcta a qué categoría pertenece cada uno de los puntos. Para lograr una clasificación adecuada, se debió considerar a cada punto en su forma 3D. Ground routine (Rutina de suelo), es un algoritmo que clasifica los puntos de tierra mediante iteración, de un modelo de superficie triangulada.

Los ejes xy permiten determinar la localización correcta de cada punto en la superficie con respecto a la ortogonal del suelo, para la determinación de límite y bordes de las entidades, mientras que el eje $z$, ayuda a determinar la entidad que corresponde él 0 los puntos que tienen idénticos valores xy.

En este proceso se cuenta con apoyo de las fotografías realizadas en el vuelo durante la captación de datos, las que son útiles para estimar con mayor precisión los límites entre entidades que cuentan con puntos que tienen idénticos o similares valores $\mathrm{x}, \mathrm{y}, \mathrm{z}$.

Esta herramienta también permite calcular la cantidad de puntos dentro de cada límite de bloque. El proyecto cuenta con un total de 32.969.027 puntos de todas las categorías en una superficie total de $15.062 .160 \mathrm{~m}^{2}(1.506,216 \mathrm{ha})$. En la tabla $\mathrm{N}^{\circ} 1$, se muestra el detalle de las categorías.

Una desventaja que presenta el sistema láser en IRC (Infrarrojo cercano), es que debido a la longitud de onda en la cual se propaga $(800 \mathrm{~nm}$ a $2.500 \mathrm{~nm}$ del espectro electromagnético), no puede captar reflectancia de las superficies acuáticas, ya que por sus propiedades éstas absorben la radiación a medida que la longitud de onda aumenta, y cuando llegan a la longitud de onda del IR la radiancia ya es casi nula (Chuvieco, 1995).

\begin{tabular}{|c|c|}
\hline Clase & Cantidad \\
\hline Suelo & 29.532 .764 \\
\hline Construcción & 3.436 .263 \\
\hline Total & 32.969 .027 \\
\hline
\end{tabular}

Tabla No1 Puntos por categoría. Fuente: Elaboración propia. (Se calcula una densidad de 0,673 puntos por $\mathrm{m}^{2}$ de todas las categorías y una de 0,603 puntos por $\mathrm{m}^{2}$ de la categoría suelo). 
Para representar el relieve del río Rehue se debió ajustar y corregir los puntos en su valor $z$, puesto que no se contaron con datos batimétricos. Técnica que permite obtener los parámetros de la geometría del cauce fluvial relativo a la profundidad $(d)$, y amplitud (w), por lo que se obtuvo la geometría por medio de las características geomorfológicas del mismo a través de la técnica de fotointerpretación (detectando, identificando, analizando y deduciendo) (Servicio Aerofotogramétrico de la Fuerza Aérea de Chile y Pontifica Universidad Católica de Chile, 2003), donde se bajó en 0,4 a $1 \mathrm{~m}$ su profundidad sobre la lámina de agua.

El módulo TerraScan cuenta con herramientas que permiten la creación de Modelos de Superficies Editables (Create Editable Model), el cual fue utilizado para la creación del perfil longitudinal y los perfiles transversales del río.

Esta caja de herramientas permite: crear modelos de superficie editable, asignar clase a un punto láser, clasificar puntos usando pincel, clasificar puntos dentro de la cerca, clasificar puntos sobre la línea de vista de sección,

clasificar puntos por debajo de la línea de vista de sección, clasificar puntos cerca de la línea de la vista de sección, añadir un punto sintético con un clic $^{5}$, clasificar puntos de vegetación fuera del suelo, establecer elevación de puntos dentro de un polígono y reconstruir el modelo después de la clasificación (de izquierda a derecha).

Se incorpora la clasificación de las construcciones circundantes al río con el objetivo de realizar el modelamiento, considerando la urbanización e identificar su grado de incidencia en la inundación

\section{Modelación sobre la superficie (MDS)}

Trabajo en HEC-GeaRas y HEC-RAS (Obtención de áreas de inundación).

Con la obtención de la clasificación de los puntos, se exportan las clases de suelo y construcción en formato LAS desde TerraScan a ArcGis 10.5. Desde acá se crean un MDT (puntos de suelo) y un MDS (puntos de suelo y construcción).

HEC-GeoRAS es una extensión para ArcGis 10 creada por el HEC (Hydrologic Engineering Center) del Cuerpo de Ingenieros del Ejército de Estados Unidos (United States Army Corps of Engineers) y ESRI (Environmental System Research Institute), que permite obtener, exportar e importar características de la geometría del cauce fluvial como su dirección, bordes, perfil longitudinal y transversales, todo ello sobre un TIN (Trianguled Irregular Network), (Universidad de Granada, 2013), (Figura 6).

Se crea un archivo en ArcGIS (mxd) en el cual se dibujan los vectores (geometría del cauce). Éstos (River 3D, Flowphats, XSCutLines 3D y Banks), mediante la herramienta de HEC-GeoRas, adquieren la forma 3D respecto de los valores del TIN, los que se exportan en un formato $\mathrm{xml}$ para ser utilizados en HEC-RAS.

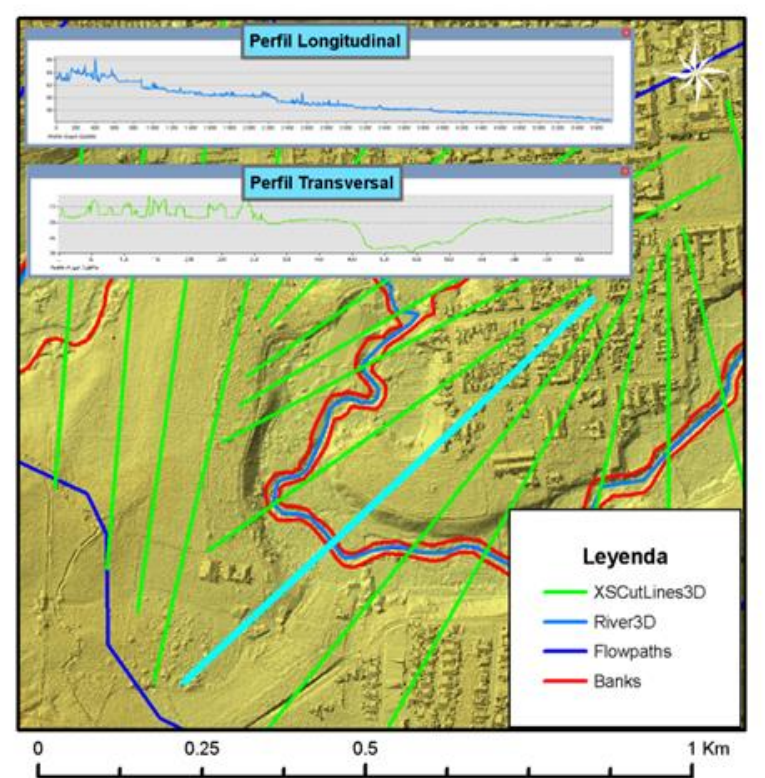

Figura 6. Geometría del cauce fluvial sobre un TIN (Vista ArcGIS 10.5)

En HEC-RAS (Hydrologic Engineering CenterRiver Analysis System), aplicación utilizada para modelamiento numérico en ríos, se importaron los datos xml de la geometría del cauce.

La modelación se realizó en una dimensión, la cual exige parámetros geométricos y otros físicos del cauce fluvial.

\section{Parámetros geométricos}

Se utiliza el sistema de unidades métrico en la modelación y además se ajustan la cantidad de nodos en los perfiles transversales que exigen el software, el que no debe ser superior a 500.

\footnotetext{
${ }^{5}$ Agrega puntos que no existen o no fueron tomados en la captación de datos
} 


\section{Parámetros físicos}

Estos corresponden a datos del caudal, como la rugosidad y el volumen entre otros.

La $n$ de Manning, expresa la cantidad de resistencia que tiene el desplazamiento del agua en un cauce natural o artificial, el cual está en función de factores como la rugosidad, vegetación, alineamiento, sedimentación y caudal entre otros (Ingeniería HIdráulica y Ambiental, 2018).

El valor de Manning se obtuvo a través del método de Cowan, el cual combina una serie de factores (Ingeniería HIdráulica y Ambiental, 2018).

$$
n=\left(n_{0}+n_{1}+n_{2}+n_{3}+n_{4}\right) n_{5}
$$

Donde:

\begin{tabular}{|c|c|c|c|}
\hline \multicolumn{2}{|c|}{ CONDICIÓN DEL CANAL } & FACTOR & VALORES \\
\hline \multirow{4}{*}{ MATERIAL } & Tierra & \multirow{4}{*}{$n_{o}$} & 0.020 \\
\hline & Roca & & 0.025 \\
\hline & Grava fina & & 0.024 \\
\hline & Grava gruesa & & 0.028 \\
\hline \multirow{4}{*}{$\begin{array}{l}\text { GRADO DE } \\
\text { IRREGULARIDAD }\end{array}$} & Ligero & \multirow{4}{*}{$n_{1}$} & 0.000 \\
\hline & Menor & & 0.005 \\
\hline & Moderado & & 0.010 \\
\hline & Severo & & 0.020 \\
\hline \multirow{3}{*}{$\begin{array}{l}\text { VARIACIONES EN LA } \\
\text { SECCIÓN } \\
\text { TRANSVERSAL DEL }\end{array}$} & Gradual & \multirow{3}{*}{$n_{2}$} & 0.000 \\
\hline & Ocasional & & 0.005 \\
\hline & Frecuente & & $0.010-0.015$ \\
\hline \multirow{4}{*}{$\begin{array}{l}\text { EFECTO RELATIVO DE } \\
\text { OBSTÁCULOS }\end{array}$} & Despreciable & \multirow{4}{*}{$n_{3}$} & 0.000 \\
\hline & Menor & & $0.010-0.015$ \\
\hline & Apreciable & & $0.020-0.030$ \\
\hline & Severo & & $0.040-0.0060$ \\
\hline \multirow{4}{*}{ VEGETACIÓN } & Baja & \multirow{4}{*}{$n_{4}$} & $0.005-0.010$ \\
\hline & Media & & $0.010-0.025$ \\
\hline & Alta & & $0.025-0.050$ \\
\hline & Muy Alta & & $0.050-0.100$ \\
\hline \multirow{3}{*}{ GRADO DE SINUOSIDAD } & Menor & \multirow{3}{*}{$n_{5}$} & 1.000 \\
\hline & Apreciable & & 1.150 \\
\hline & Severo & & 1.300 \\
\hline
\end{tabular}

Tabla 2. Coeficiente de Rugosidad de Manning

La Tabla 2 detalla los factores a utilizar en la simulación en el presente estudio.

La vegetación en el tramo 2 presenta gran concentración y de elevada altura, junto con la morfología, debido a la presencia de meandros hasta llegar a confluencia con tramo 1.

Los ríos aluviales, característicos por poseer pendientes bajas, desarrollan recodos en la trayectoria del flujo del cauce y se forman con los propios depósitos que van acumulando. Éstos presentan inundaciones anuales o bianuales en las estaciones lluviosas (Figura 14), (Strahler, 1989).
Los datos del caudal (volumen en $\mathrm{m}^{3} / \mathrm{seg}$ ) dominante fueron adquiridos de manera directa de la página oficial de la DGA (Dirección General de Aguas). En ella se seleccionó la estación fluviométrica de Río Rehue en Quebrada Culén, siendo la más próxima agua arriba en coordenadas 692784 E y $5798416 \mathrm{~N}$.

El caudal se obtuvo con las medias mensuales del mes de julio de 1997 a septiembre de 2017, siendo julio y agosto los meses que obtuvieron los valores más altos con 16,06 $\mathrm{m}^{3} / \mathrm{seg}$ y $15,97 \mathrm{~m}^{3} / \mathrm{seg}$, respectivamente.

La relación estrecha entre Velocidad media $(V)$ y Área transversal $(A)$ determina el caudal del cauce $(Q)$. Cuando una sección transversal disminuye, la velocidad del caudal aumenta o también por efecto de la gradiente (Strahler, 2004).

$$
Q=V A
$$

El punto de confluencia (Figura 7) de los cauces tiene una cota de $58,72 \mathrm{~m}$. El Tramo 1 hasta alcanzar el punto de confluencia, tiene una pendiente de $0.086 \%$ (Figura 8), mientras que el Tramo 2 la gradiente es de $0.134 \%$, lo que ocasiona un aumento de velocidad del agua (Figura 9), aun así cuando se advierte que el mismo tramo presenta llanuras de inundación.

En la Figura 7, la extensión de inundación se presenta en todo el Tramo 2, pero con profundidades muy leves que alcanzan hasta los 1,3 $\mathrm{m}$ para un caudal de inundación de $200 \mathrm{~m}^{3} / \mathrm{seg}$.

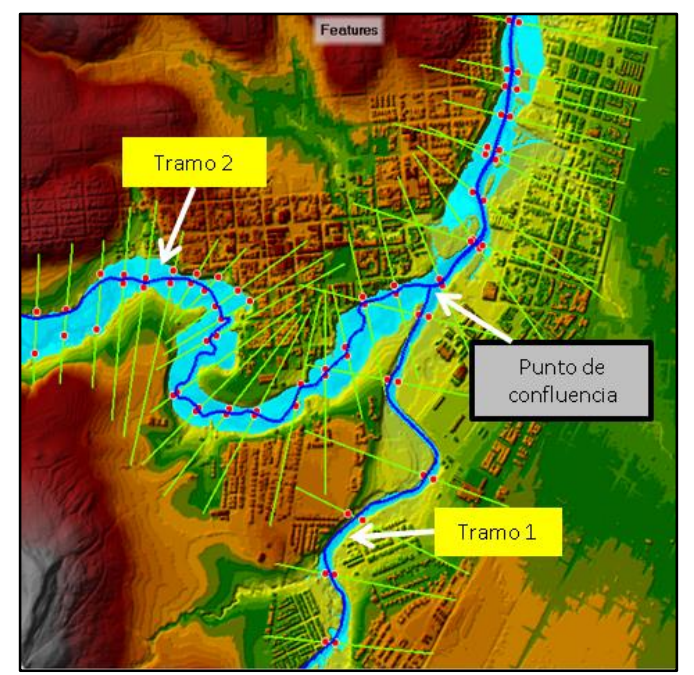

Figura 7. Parámetros geométricos y físicos integrados que permiten la simulación. 


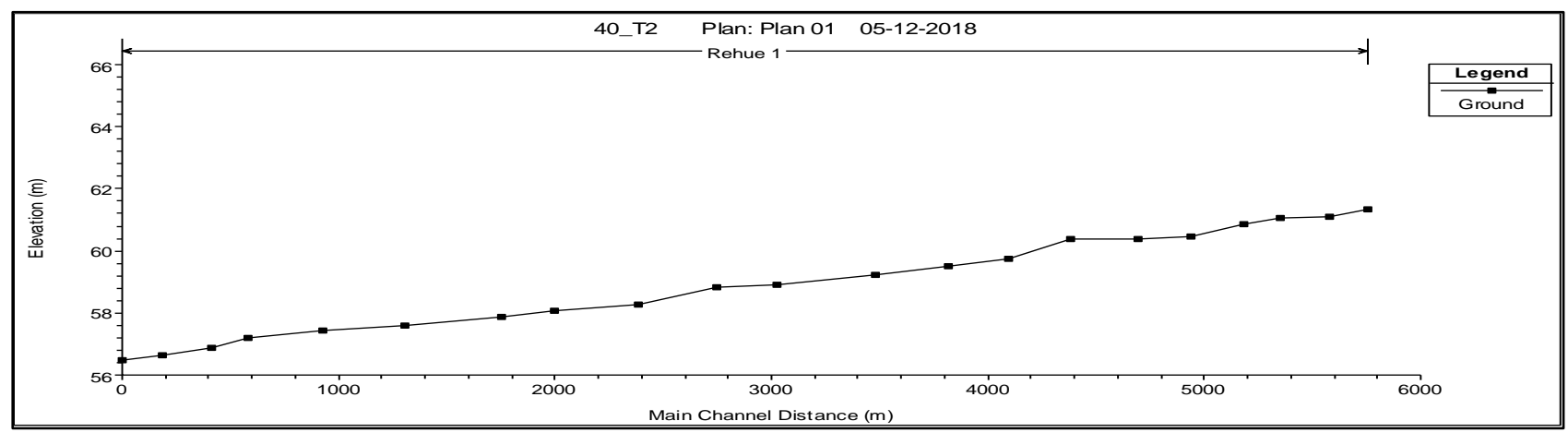

Figura 8. Perfil longitudinal Tramo 1

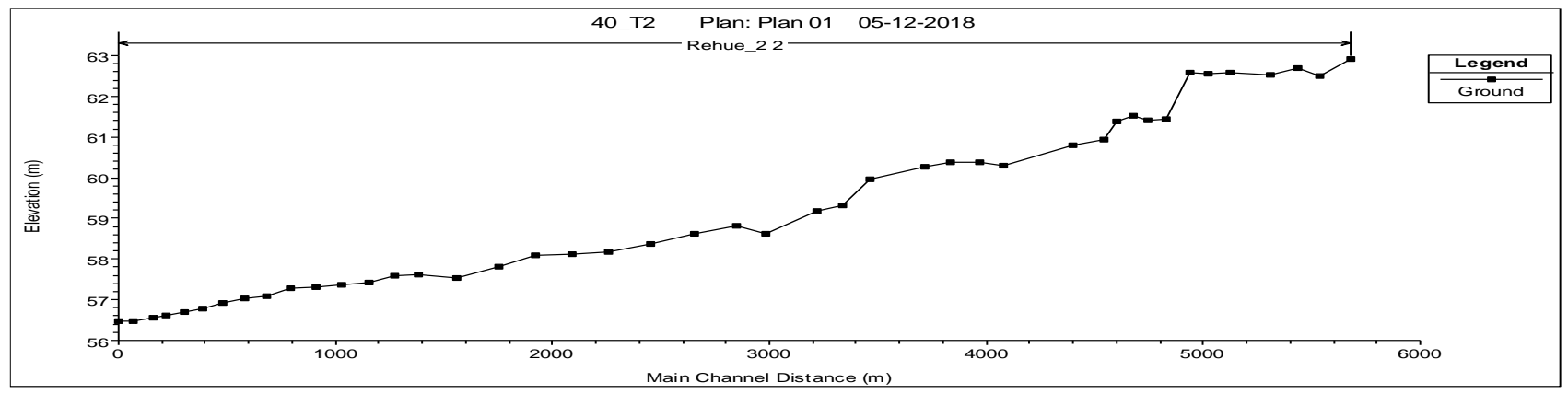

Figura 9. Perfil longitudinal Tramo 2

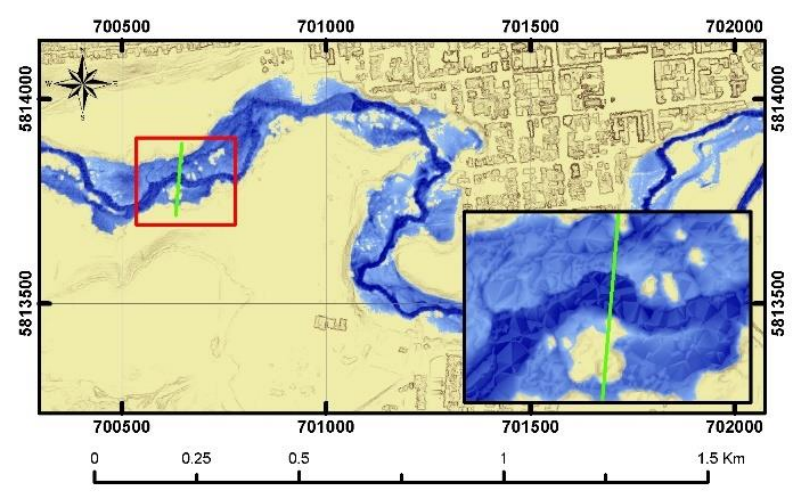

Figura 10. Tramo 2, áreas de inundación con caudal de $20 \mathrm{~m}^{3} / \mathrm{seg}$. Fuente: elaboración propia.

El perfil transversal de la figura 11, le corresponde a la figura 10 y el de la figura 12 al de la figura 13 . Ambos obtenidos de HEC-RAS.

La aplicación del modelo en las Figuras 10 y 13, se realizó con un caudal de $20 \mathrm{~m}^{3} / \mathrm{seg}$., y una $n$ de Manning de 0.081 para tramo 1 y 0.109 para el 2 .

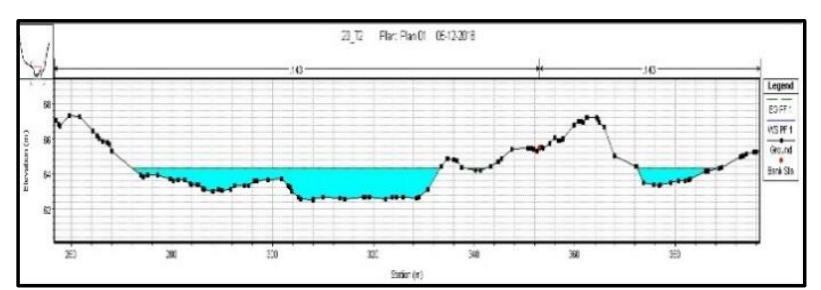

Figura 11. Perfil de figura 10. Fuente: elaboración propia.

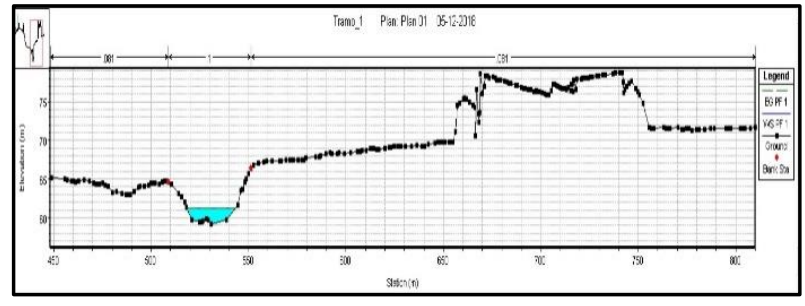

Figura 12. Perfil de figura 13. Fuente: elaboración propia. 


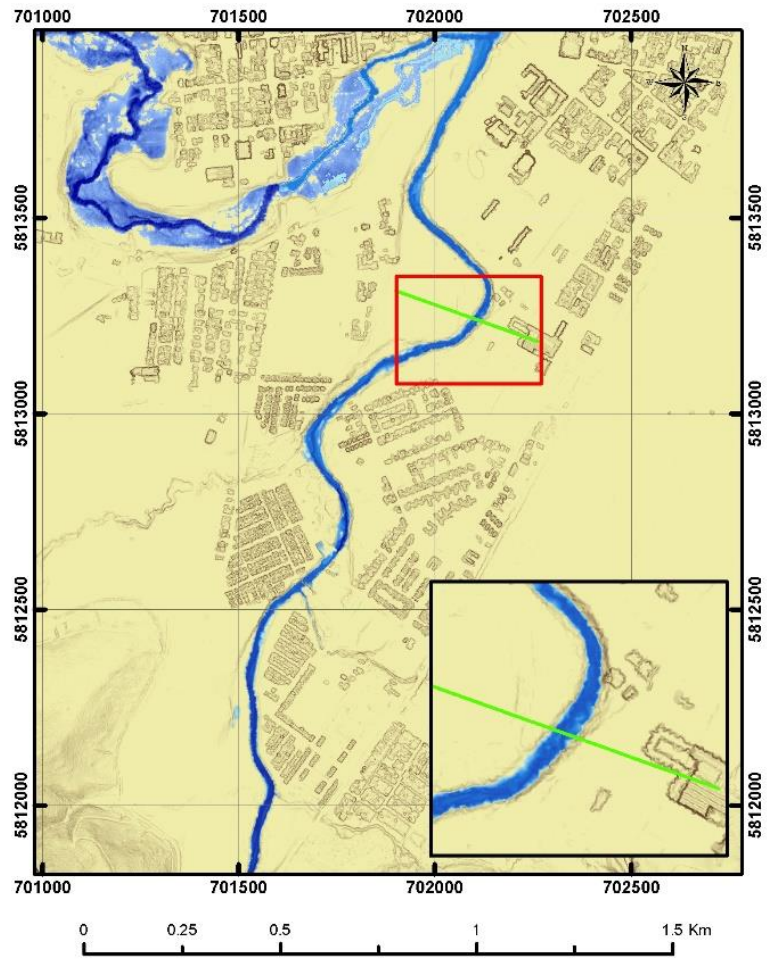

Figura 13. Tramo1, se presenta con bordes más pronunciados en gradiente. Fuente: elaboración propia.

Las velocidades que describe la trayectoria del flujo en el tramo 2 son altas, más aún, como se aprecia en la Figura 16 (Velocidades), cuando las secciones transversales disminuyen. La velocidad del agua puede estar en función de la pendiente, área de la sección transversal, profundidad del cauce y rugosidad del suelo (Strahler, 2004).

La velocidad de la corriente, por otra parte, también está relacionada con la gradiente y la profundidad. Cuando existe un mayor gradiente, se induce que el flujo se trasladará a mayor velocidad. Respecto a la profundidad, un cauce con una misma gradiente y una corriente profunda, el flujo de agua circula con mayor rapidez que en corrientes con menor profundidad. Ello debido a que su porcentaje de pérdida de energía cinética relacionado a la fricción con el lecho es menor. La velocidad media sería proporcional al producto de la raíz de la gradiente (en porcentaje) y la raíz de la profundidad media de la sección transversal.

\footnotetext{
6 Tagged Image File Format, formato de archivo de imágenes con etiquetas, en español. Es un formato de archivo concebido para almacenar imágenes de mapa de bits.
}

Hecha la simulación en HEC-RAS, los datos obtenidos se exportan en formato $\mathrm{xml}$, los que posteriormente se importan en HEC-GeoRAS (ArcGIS). A partir de ello, se transforman los datos a shape, creando todos los datos sobre un TIN.

Cabe señalar, que HEC-GeoRAS cuenta con un módulo para trabajar la geometría del cauce (RAS Geometry) y otro para generar los mapas creando un layer (RAS Mapping).

En la vista general se apoya la imagen con ortofotos en formato tif6 (Figura 16., Ortofoto) de tamaño de pixel de $10 \times 10 \mathrm{~cm}$ y su archivo de referencia en $t f w^{7}$.

La microtopografía obtenida con el LIDAR, es relevante en la obtención de datos referidos a la vegetación de ribera y microrelieve en el estudio, alcanzando precisiones centimétricas y milimétricas, todo apoyado con ortofotos de alta resolución (Aplicaciones de la teledetección láser (LIDAR) en la caracterización y gestión del medio fluvial, 2006).
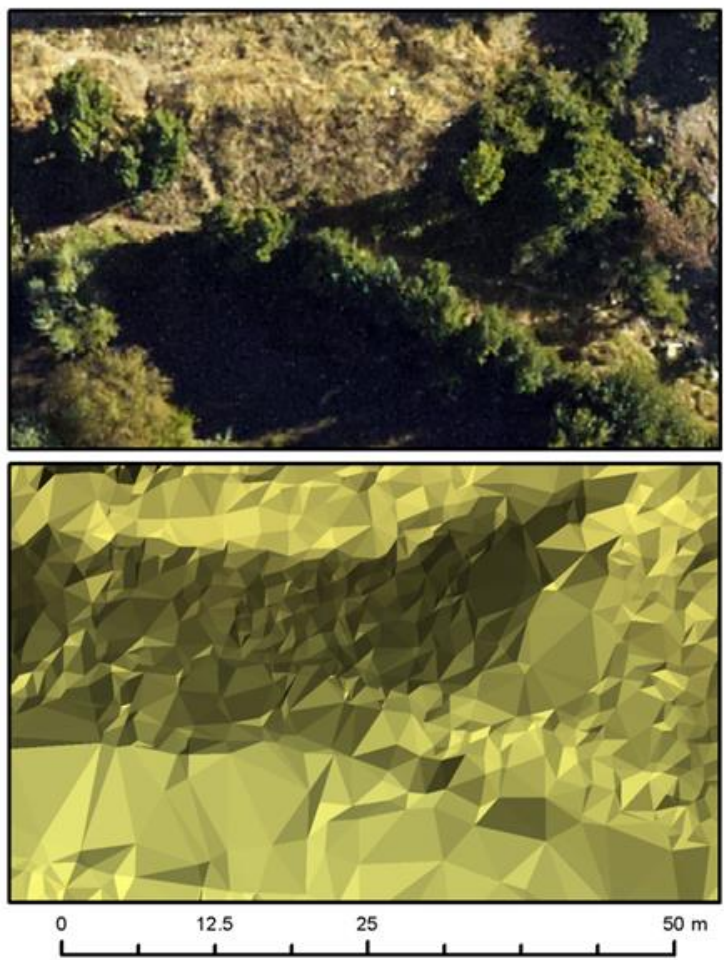

Figura 14. Imagen de relieve asistida por ortofoto (Escala 1:800). Fuente: elaboración propia.

\footnotetext{
7 TFW es el archivo auxiliar que es requerido para dar geolocalización al archivo raster en formato tif.
} 
Propiedades topográficas de la superficie.

La Figura 20, representa propiedades topográficas del terreno (pendiente, orientación, profundidad y elevación). La elevación más alta para el fondo del cauce, corresponde a la cota $61,34 \mathrm{~m}$ del tramo 1 y $62,70 \mathrm{~m}$ del tramo 2, mientras que la cota más baja en el fondo del cauce, corresponde a $56,5 \mathrm{~m}$ para ambos tramos, (Figura 10 y 13). De ello se obtiene la pendiente para el tramo 1 de 0,084 por ciento y 0,109 para el tramo 2.

La precisión y densidad de los puntos del sistema LIDAR permite generar un archivo ráster con un pixel de tamaño de 0,5 $\mathrm{m}$ y con él se generan Fill8, Flow Direction ${ }^{9}$, Flow Accumulation ${ }^{10}$ y Basin $^{11}$ (Figura 15), todas ellas herramientas de Hydrology propias de ArcGis, el cual se incorpora al SIG en la tercera fase.

Uno de los indicadores del grado de bifurcación es el orden de corriente. La corriente de orden 1 indica que no tiene tributarios y una de orden 2 que tiene tributarios de orden 1 (Grupo de Investigación en Transporte de Sedimentos, 2007)

La herramienta acumulación de flujo, permite obtener, mediante un archivo ráster, el peso de cada celda, derivado éste de la acumulación del peso de las celdas que fluyen hacia la celda de pendiente descendente (ArcGIS for Desktop).

Para la clasificación de escorrentía se utilizó el Método de Strahler, disponible en ArcGis 10.5 (ArcGIS for Desktop).

En la Figura 18, se observa que los distritos El Rosario, Centro, Estación y Hospital contienen en su mayoría un relieve con pendientes más pronunciadas. Ello ha provocado eventos de remoción en masa que afectan a la población (Subsecretaría de Desarrollo Regional y Administrativo, 2015).

Existen sectores cercanos a la ladera del río, con un relieve con diferencia de altura abruptos, como los distritos censales Centro y Hospital.

Estudios y evaluaciones realizados por autoridades locales y regionales, han arrojado resultados donde indican que las características del relieve junto a la hidrología de la zona, producen eventos de remoción en masa e inundaciones con frecuencia, siendo estos eventos los que tienen los índices de vulnerabilidad más alta entre los evaluados.

\footnotetext{
8 Rellena hendiduras en una superficie de ráster para quitar pequeñas imperfecciones en los datos.

${ }^{9}$ Crea un ráster de dirección del flujo desde cada celda hasta su vecina o vecinas con pendiente descendente.
}

En ambos eventos, las viviendas afectadas son de material ligero y perteneciente a familias en situación de vulnerabilidad social (Subsecretaría de Desarrollo Regional y Administrativo, 2015).

El estudio de las aguas es objeto de la Hidrología, aunque dependiendo del punto de vista a cual esté orientado su análisis, podrán ser otras las disciplinas que se ocupen de ella para estudios complementarios. El caso puntual de este estudio, se orientó a determinar el comportamiento de agua y su distribución geográfica según el relieve donde interactúa, siendo esto propio de la Hidrografía, no obstante, para la simulación en HEC-RAS, se enfocó en sus aspectos físicos, tarea que se ocupa la Hidráulica. En general, se refiere al agua en su manifestación superficial (Figura 18) (Sala Sanjaume, y otros, 1999).

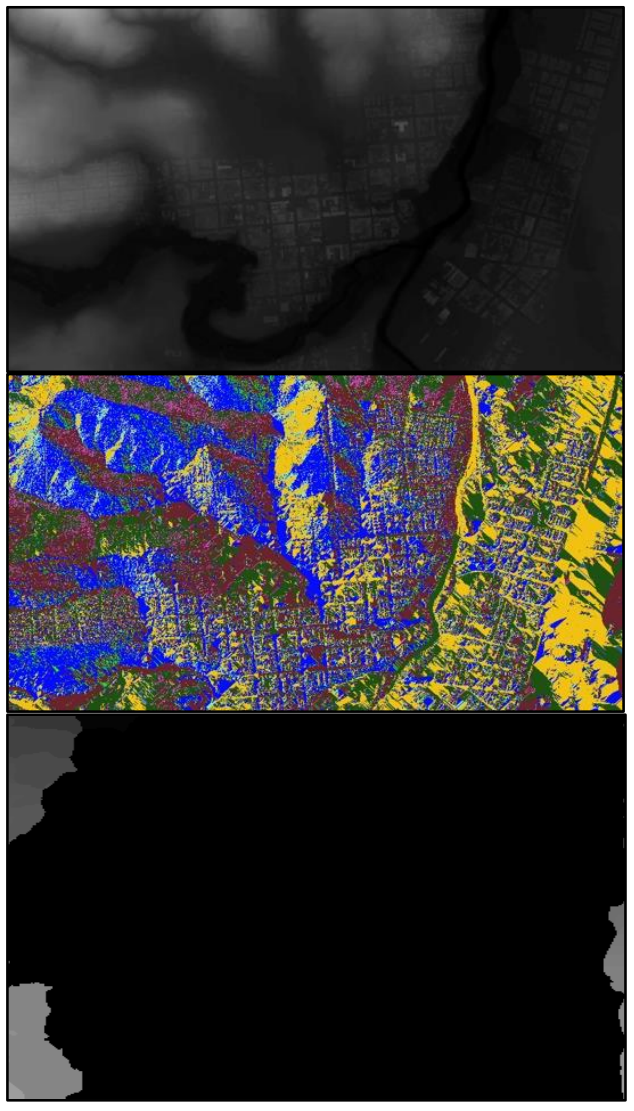

Figura 15. Hydrology. De arriba hacia abajo: Fill, Flow Direction y Basin. Fuente: elaboración propia.

\footnotetext{
10 Crea un ráster de flujo acumulado en cada celda Opcionalmente, puede aplicar un factor de peso.

11 Crea un ráster que delinea todas las cuencas de drenaje.
} 
Aplicación de la tecnología láser (LiDAR)en la zonificación de áreas de inundación del río Rehue en la ciudad de Angol Alejandro Rodríguez Parra, Gonzalo Ortega Candia

\section{SIMULACIONES}

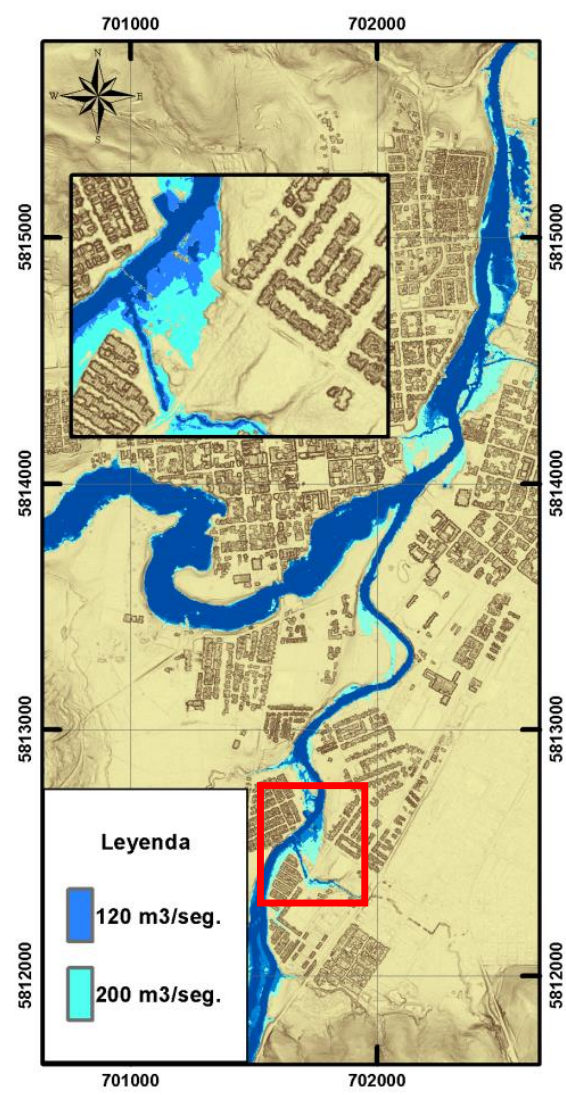

ESCALA: $1: 40000$
VELOCIDADES

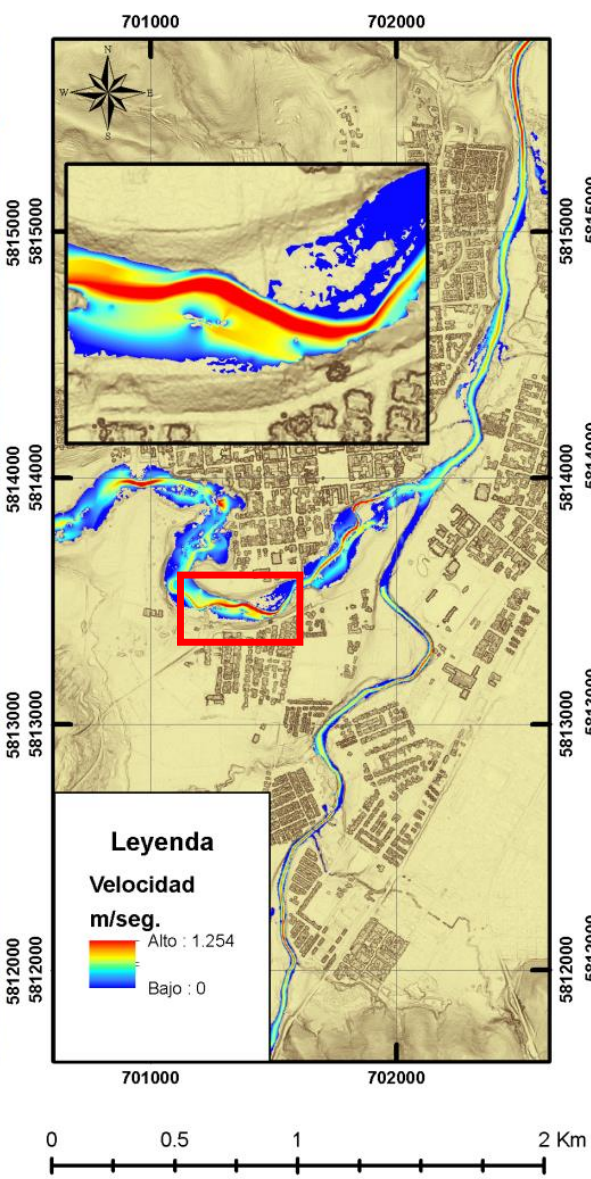

ORTOFOTO

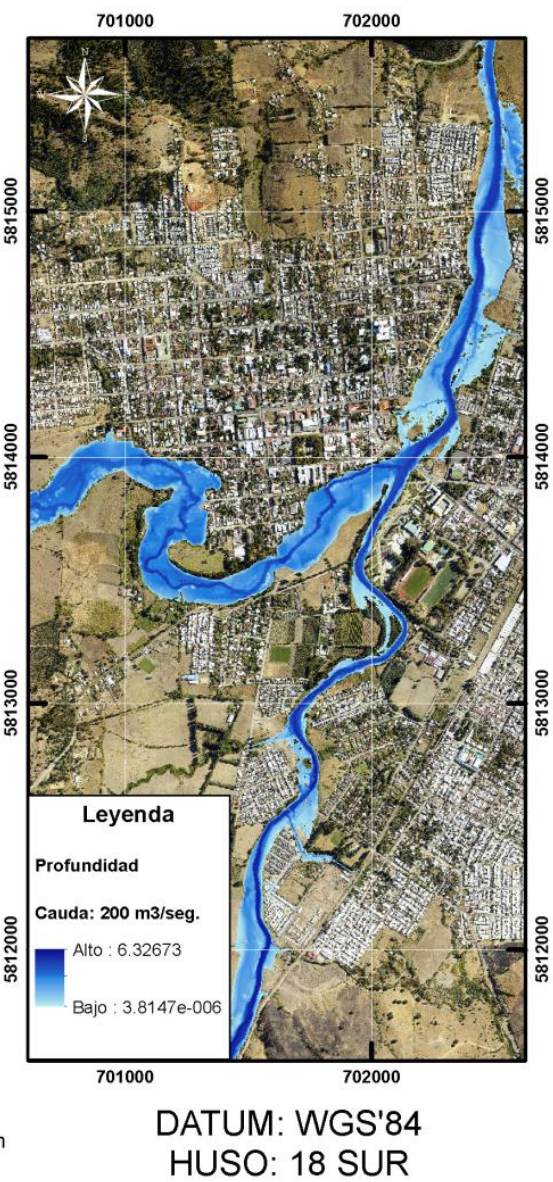

Figura 16. Mapas de simulaciones, velocidad y vista general de ortofoto. Fuente: elaboración propia.

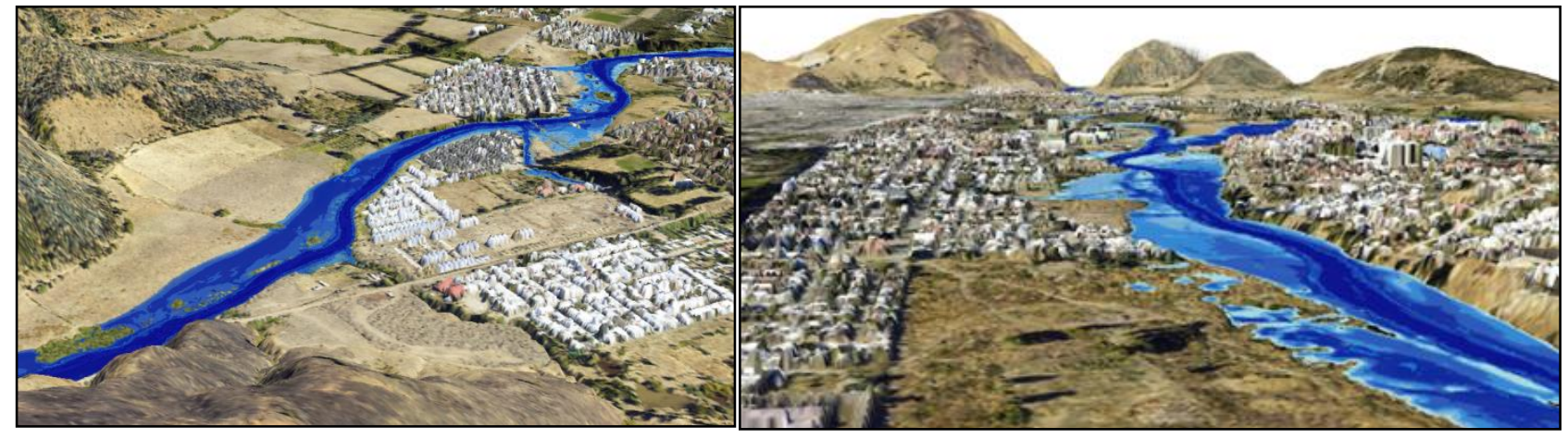

Figuras 17. Vista panorámica en 3D desde ArcGIS 10.5 (ArcScene). Fuente: elaboración propia. 


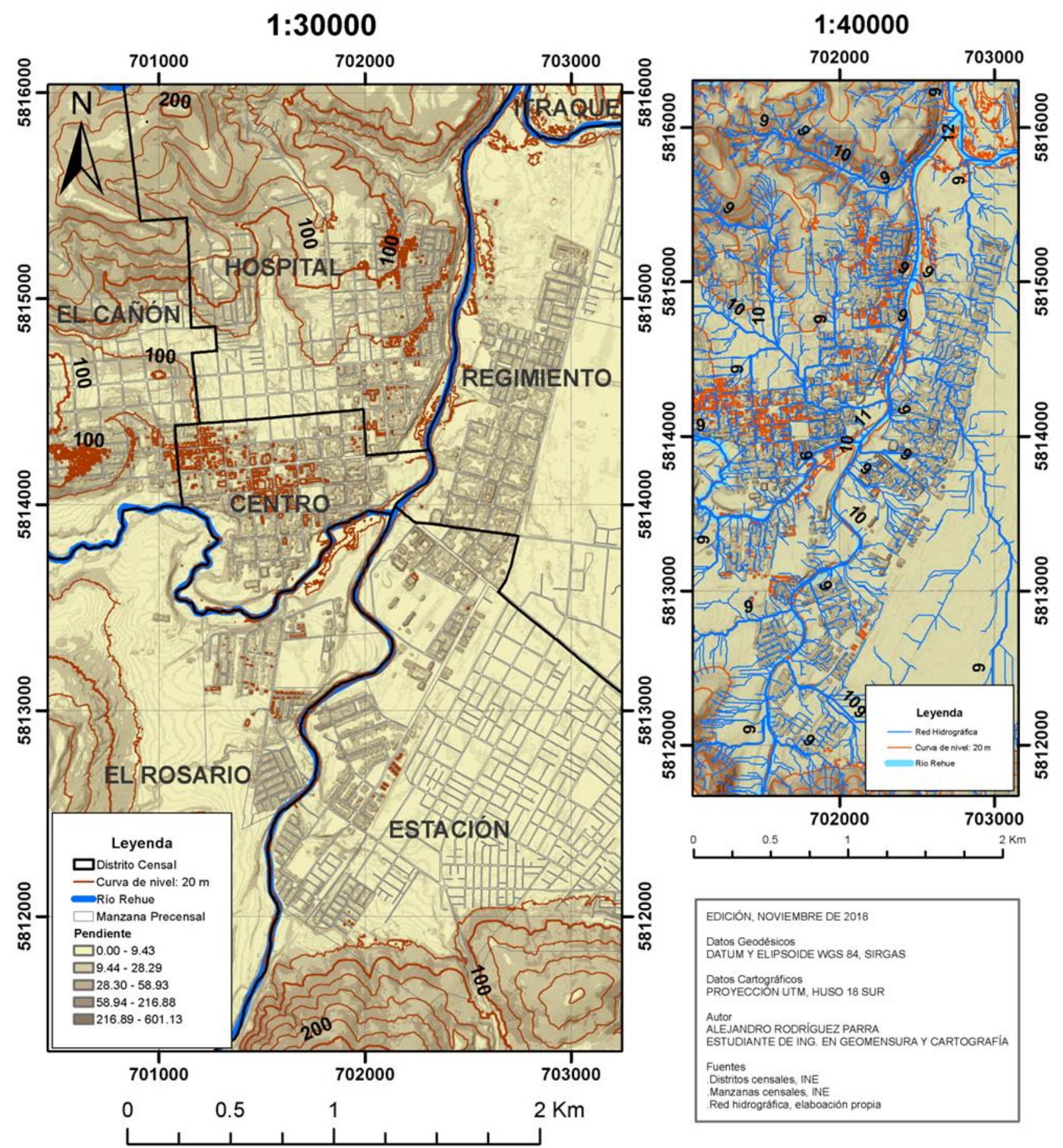

Figura 18. Mapa de pendientes y elevaciones. Figura 19, Mapa de escurrimiento. ${ }^{12}$ Fuente: elaboración propia.

\footnotetext{
12 Método Strahler (Strahler, 1989).
} 
Integración de Datos Geográficos.

La integración de datos geográficos a todo tipo de aplicación, dispositivo, plataforma y sistemas, es necesario para interrelacionar productos entre diversas disciplinas en el área de la geomática y así obtener información geográfica aplicable. Por ello se implementa el producto fotogramétrico obtenido a un SIG abreviado.

El sistema se reduce a la creación de 2 Model Builder $^{13}$ de manera sucesiva. El primero, a partir de los shape ${ }^{14}$ de inundación obtener las diferencias de áreas entre los diferentes caudales (superposición) y proximidad de viviendas al río (conectividad), ambas de la función análisis que permiten calcular aspectos geométricoscartográficos y de los atributos del avance del agua sobre la manzana censal (Comas, y otros, 1993).

El segundo, destinado a crear, a partir de datos LIDAR, las propiedades topográficas del terreno (MDT).

El Riesgo $(R)$ se define como la relación entre el Peligro $(P)$ y la Vulnerabilidad $(V)$, donde la primera se refiere a aspectos reales de la inundación (Shape de inundación) y la segunda a las condiciones que hacen susceptible a la sociedad o bienes materiales a hacer dañados (Shape de manzanas censales) (Apel, y otros, 2009).

$$
R=P \times V
$$

En su estudio, Métodos para la evaluación de riesgos de inundación fluvial: revisión de literatura y propuesta metodológica para el Ecuador (Pinos, y otros, 2017), exponen el concepto Fuentes (F) Vías (V) - Receptores (R) - Consecuencias (C), donde Fuentes son las condiciones físicas o valores de entrada para los modelos. Vías se refiere a las rutas hacia los receptores. Los Receptores son las personas o medios que están en riesgo y las Consecuencias es él o los impactos resultantes del fenómeno.

Los modelos pueden orientarse a evaluar distintos daños y de diferentes formas, pudiendo ser físicos, económicos, sociales, morales, directos, indirectos, tangibles e intangibles (Gupiponi et al., 2014). Esto en función de su enfoque de pérdida. El enfoque empírico recolecta datos y obtiene información

\footnotetext{
13 Es un lenguaje de programación visual para crear flujos de trabajo de geoprocesamiento. Los modelos de geoprocesamiento automatizan y documentan los procesos de análisis espacial y de administración de datos (ArcGIS for Desktop).
}

después del evento, mientras que el enfoque sintético/ingeniería, utiliza datos hipotéticos o ambos (Gerl et al., 2016).

La implementación del SIG se orienta a la identificación y distribución del riesgo de inundación en el espacio geográfico con respecto a la población.

Identificación gradual del peligro

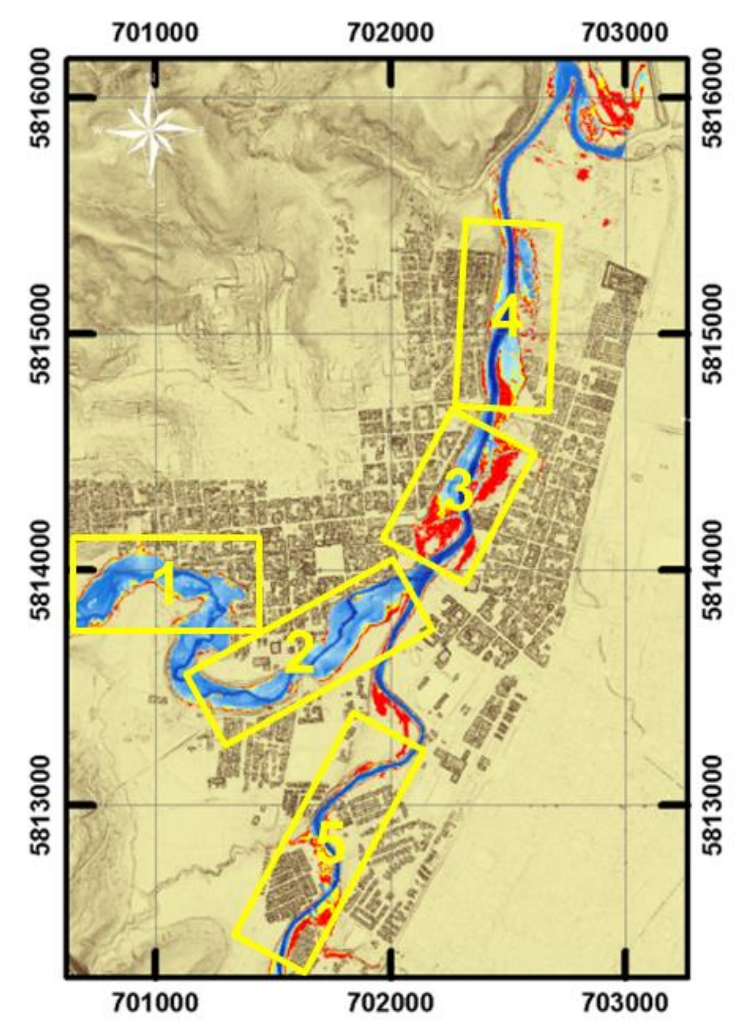

Figura 20. Descripción de sectores de inundación. Fuente: elaboración propia.

\section{RESULTADO Y DISCUSIÓN}

En la figura 16 (Simulaciones), se aprecia de manera general los resultados de las áreas de inundación en la ciudad de Angol en su tramo

\footnotetext{
14 Se utiliza para almacenar la ubicación geométrica y la información de atributos de las entidades geográficas. Las entidades geográficas de un shapefile se pueden representar por medio de puntos, líneas o polígonos (áreas) (ArcGIS for Desktop).
} 
urbano. Obsérvese que el comportamiento del cauce fluvial varía en ambos tramos, supeditado éste por factores como el relieve, geometría del cauce, la vegetación y el caudal del mismo.

La trayectoria que describe el flujo del agua en el tramo 1, tiene un comportamiento más regular hasta un caudal que alcance los $120 \mathrm{~m}^{3} / \mathrm{seg}$., alterando su comportamiento de manera más irregular una vez que se supera dicho caudal. El relieve en este tramo, presenta una geometría más pronunciada en los bordes, sumado a ello una pendiente menor que la existente en el tramo 2.

En el segundo tramo, obsérvese que los resultados arrojan un comportamiento más irregular del escurrimiento del agua sobre la superficie, ya que tan sólo con un caudal de $40 \mathrm{~m}^{3} / \mathrm{seg}$, el agua rápidamente toma un desplazamiento horizontal en su mayoría.

Después del punto de confluencia de estos cauces, el caudal es regular hasta un máximo de $80 \mathrm{~m}^{3} / \mathrm{seg}$, luego adquiere un comportamiento similar al tramo 2.

Otro fenómeno que se aprecia en la figura 16 (Velocidades), advierte que la velocidad de avance del agua en ambos tramos es desigual. En el tramo 1 las velocidades, al igual que en la dirección de flujo, son regulares, lo opuesto al tramo 2. En este último, existen sectores que alcancen altos valores en función de su geometría y pendiente, produciendo de esta manera, rápidos (donde la pendiente es más pronunciada o su sección trasversal es menor) y remansos (donde el río se hace más profundo).

En las figuras 21a y $21 b$, se observa que el agua se aleja $80 \mathrm{~m}$, en promedio, respecto a su eje principal, esto debido a que después de esa distancia, el borde del río se hace más pronunciado, características propias de los meandros o ríos aluviales. Este sector corresponde al distrito censal Centro, perteneciente al casco antiguo de la ciudad, en el que las viviendas en su mayoría son de material sólido como hormigón armado y adobe, y con un mayor distanciamiento entre las mismas.

En las figuras $22 \mathrm{a}$ y $22 \mathrm{~b}$, la trayectoria del agua es similar a las figuras anteriores, salvo que, en este caso, el desplazamiento del flujo se pronuncia hacia el sur del río, debido a la pendiente reinante, a la dirección y velocidad que acompaña al cauce desde el tramo anterior (Aguas arriba).

\footnotetext{
15 Variable cualitativa auxiliar que puede ser analizada con mayor detalle en otro estudio.
}

En las figuras $28 \mathrm{a}$ y $28 \mathrm{~b}$, después del punto de confluencia de los cauces, el agua alcanza en sectores hasta los $160 \mathrm{~m}$ de distancia respecto al eje del río. En la figura 28a, la inundación se produce hacia el oeste respecto a la dirección de avance del río, mientras que en la figura $28 \mathrm{~b}$ es hacia el este. En ambos sectores de inundación no existe edificación, pero sí ambos presentan canales que drenan hacia el río, los que conducen el agua hacia los sectores poblados en donde la concentración de la población en el sector no es muy elevada.

En las figuras 29a, la inundación se produce hacia el costado este del río, alcanzando en un sector hasta los $120 \mathrm{~m}$ respecto al eje del mismo. No se aprecian viviendas afectadas, pero sí una alta cantidad de habitantes cercanos al área de inundación. En la figura 29b, la dirección de inundación también es hacia el este, pero en el área afectada no se presentan viviendas en la cercanía, y el relieve se presenta de manera irregular con una vegetación baja de tipo matorral.

En la figura $30 \mathrm{a}$, la inundación se produce inmediatamente hacia el oeste, terrenos en los cuales no existe ningún tipo de edificación. El sector poblado se encuentra hacia el este del río, lugar que se ve afectado sólo cuando el caudal alcanza los $250 \mathrm{~m}^{3} / \mathrm{seg}$. Cabe señalar que las viviendas afectadas están dentro del distrito censal Estación, el cual entre 1993 y 2012 tuvo un crecimiento de 2.313 viviendas sociales.

En la figura 30b, se aprecia la inundación hacia ambos costados del río y en sectores no poblados, pero muy cercano a viviendas con una alta densidad de población y en algunos sectores no se cuenta con información censal (polígono amarillo). En la figura $30 \mathrm{c}$, el área inundada no supera en promedio los $30 \mathrm{~m}$ respecto al eje del río, debido a las condiciones del relieve, pero se advierte que sólo un pequeño sector se encuentra próximo al área de inundación.

Estas tres últimas figuras del sector 5 pertenecen al distrito censal Estación, con un alto crecimiento de viviendas sociales, por lo cual existen zonas prioritarias (delimitado con línea amarilla) en el área de estudio, las cuales fueron determinadas por el MINVU15.

Los resultados arrojados por las simulaciones son evidentes. La tecnología LIDAR permitió obtener una precisión en los datos, tanto planimétricos 
como altimétricos de $\pm 10 \mathrm{~cm}$, además de una concentración de puntos que permitió generar un DEM y TIN de alta precisión.

El nivel de detalle alcanzado fue primordial y formó la base para un buen modelamiento, propiedad que fue traspasada sistemáticamente de fase en fase. Otro valor agregado es que los datos LIDAR, a diferencia de la topografía tradicional, entrega datos de todo lo que hay sobre la superficie del terreno, permitiendo así generar un MDS, incorporando las construcciones.

La captación de puntos coordenados, de una gran extensión de terreno, en poco tiempo y de una alta precisión son las principales características de esta tecnología.

Por otra parte, el grado de vulnerabilidad, según los resultados expuestos en los mapas, puede estar en función de la exposición a la amenaza, de condiciones sociales como la calidad de las viviendas, densidad de la población y de proximidad al río entre otros.

La recurrencia y periodicidad con que se presenta el fenómeno, es decir, dos o más veces en el año,

Sector 1 .

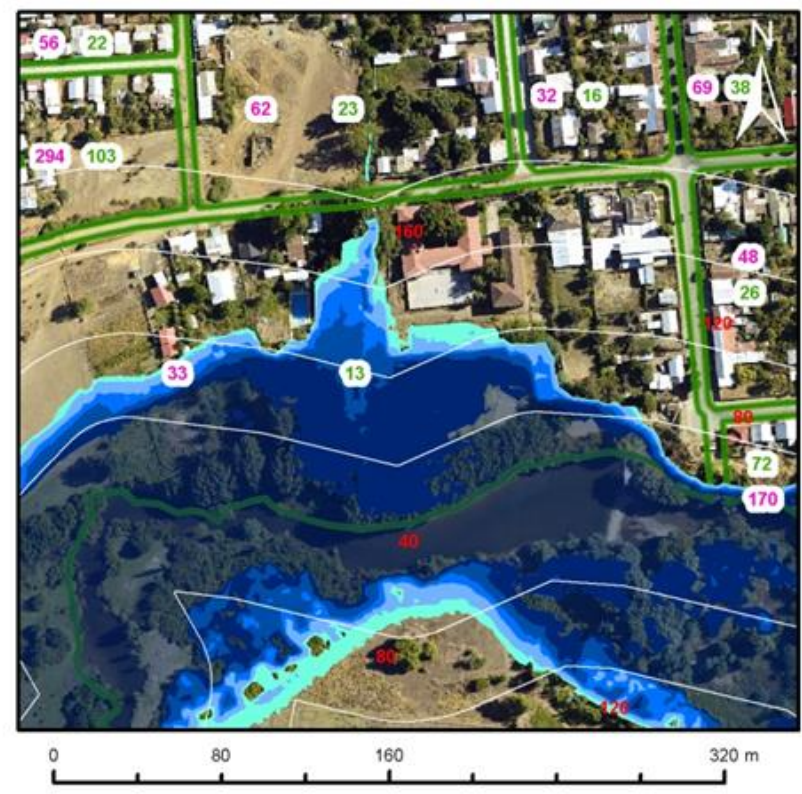

Figura 21a. Fuente: elaboración propia.

16 Las escalas entre las imágenes varían a objeto de tener la mejor representación de cada área de inundación. indican que el grado de exposición al peligro sea real y permanente.

Dado que el objetivo principal del presente estudio es determinar las áreas de inundación, su distribución y representación, no se realiza un mayor detalle del riesgo de la población, pero cabe hacer presente que la integración de más variables y atributos de entidades geográficas a un SIG avanzado, proporcionarían antecedentes relevantes para la toma de decisiones.

El estudio concluye con la visualización de imágenes por sectores, las cuales se presentan con sus respectivas escalas ${ }^{16}$. En las imágenes se podrá visualizar la proximidad de las viviendas respecto al río, a través de un MultiBuffer de proximidad de 40, 80, 120 y $160 \mathrm{~m}$. También se encontrará información de las manzanas censales donde aparce detallada numéricamente la cantidad de viviendas y cantidad de personas que ocupan dichas manzanas.

La obtención de la zonificación de las áreas de inundación fue producto de 5 simulaciones, con caudales de $40,80,120,200$ y $250 \mathrm{~m}^{3} / \mathrm{seg}$.

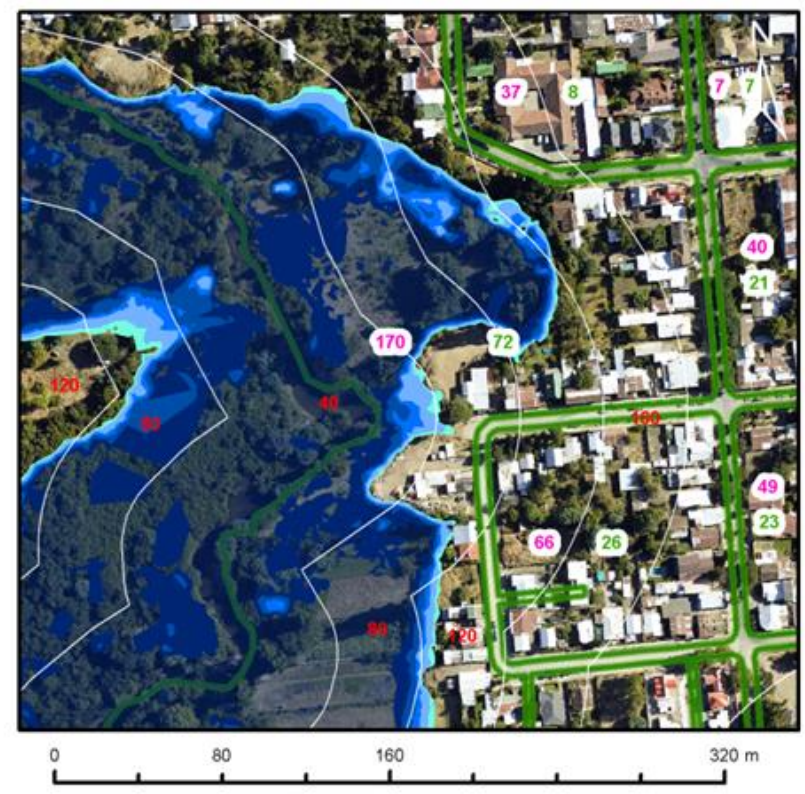

Figura 21b. Fuente: elaboración propia. 
Aplicación de la tecnología láser (LiDAR)en la zonificación de áreas de inundación del río Rehue en la ciudad de Angol Alejandro Rodríguez Parra, Gonzalo Ortega Candia

Sector 2.

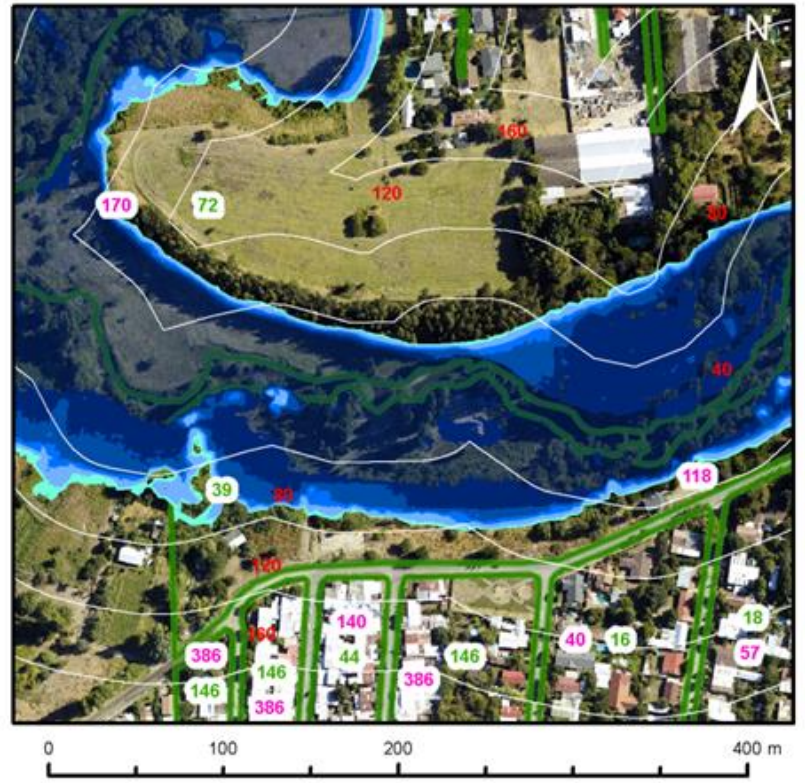

Figura 22a․ Fuente: elaboración propia.

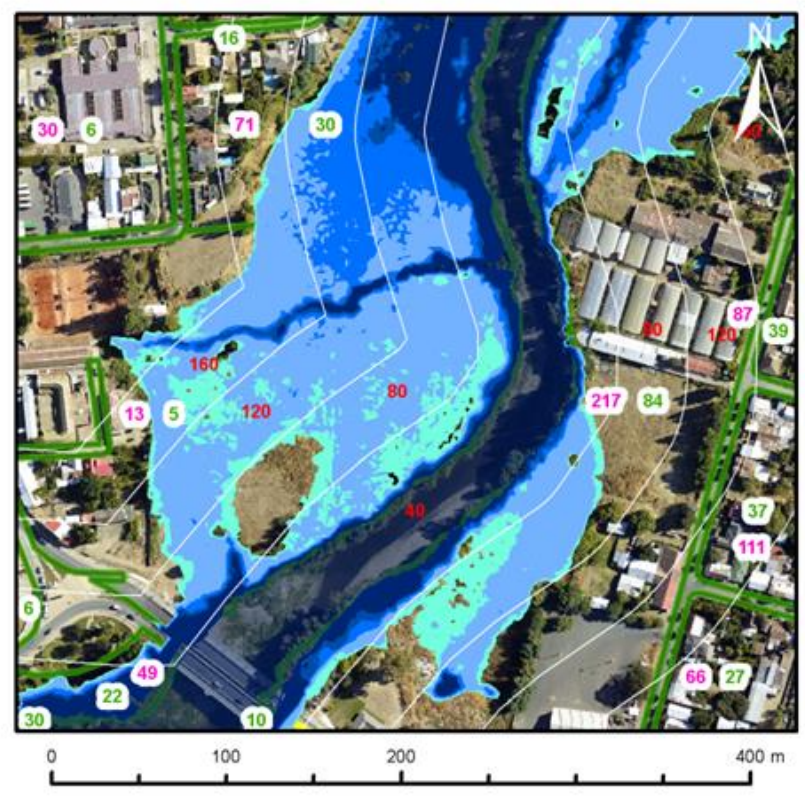

Figura 23ㄹ. Fuente: elaboración propia.

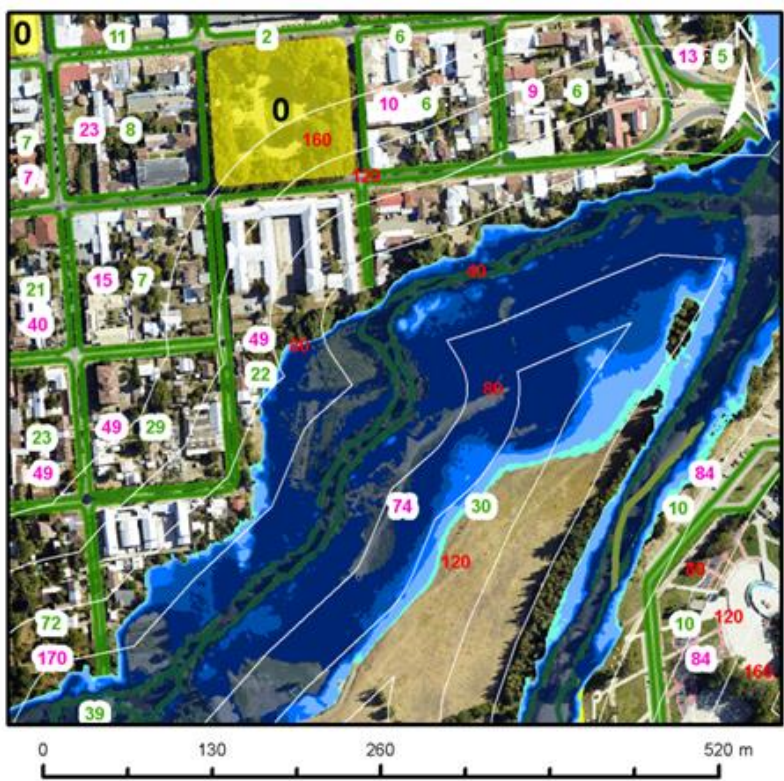

Figura 22b. Fuente: elaboración propia.

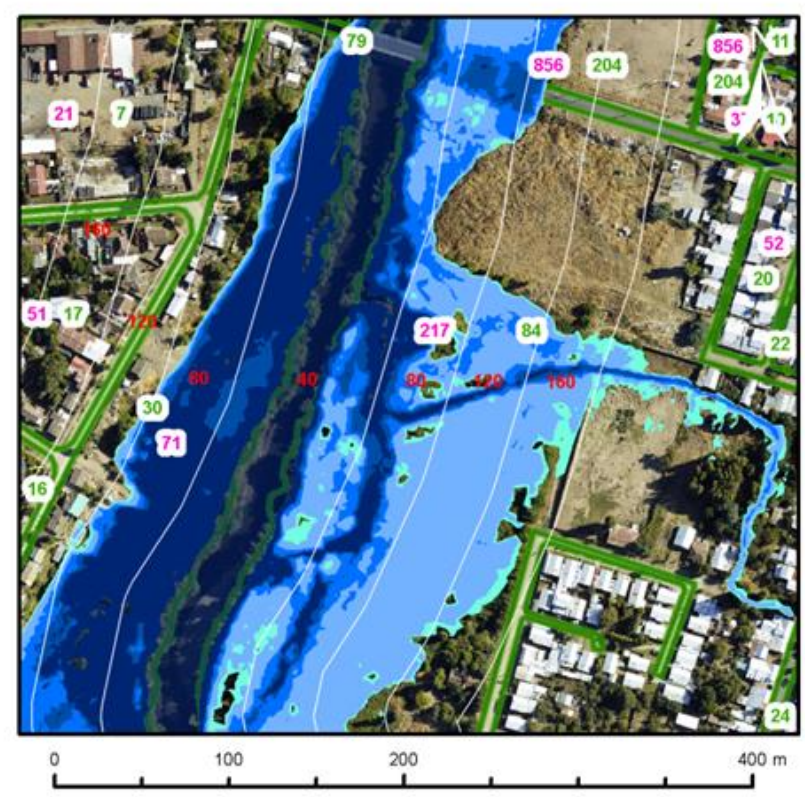

Figura 23b. Fuente: elaboración propia. 
Aplicación de la tecnología láser (LiDAR)en la zonificación de áreas de inundación del río Rehue en la ciudad de Angol Alejandro Rodríguez Parra, Gonzalo Ortega Candia

Sector 4 .

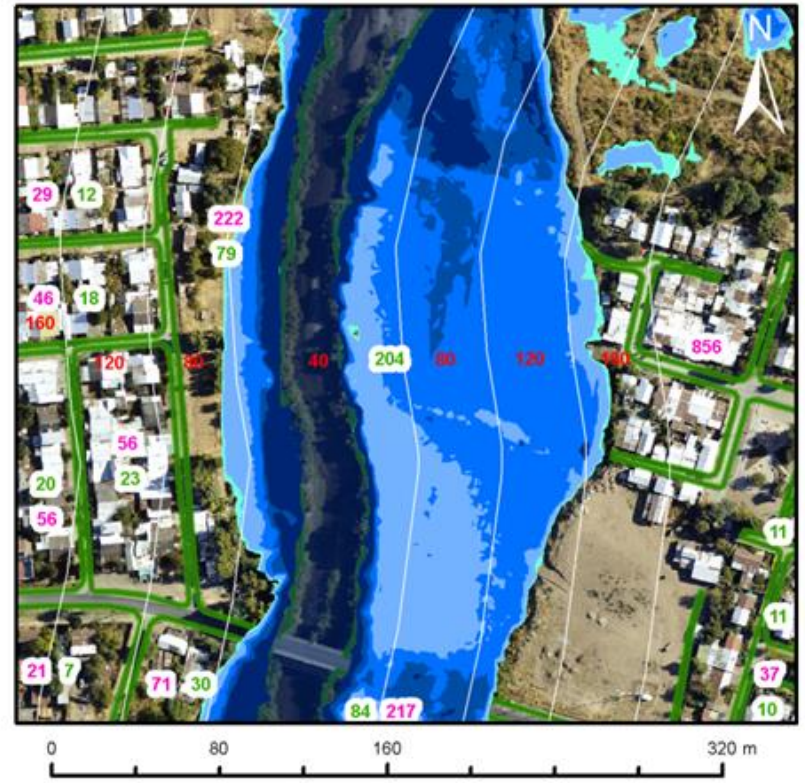

Figura 24a. Fuente: elaboración propia.

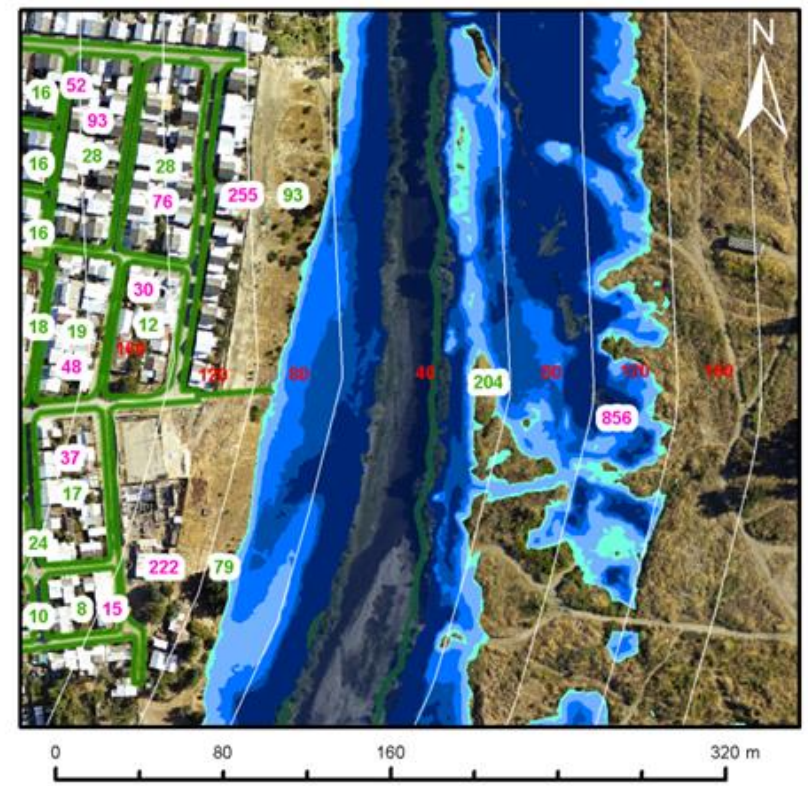

Figura 24b. Fuente: elaboración propia.

Sector 5 .

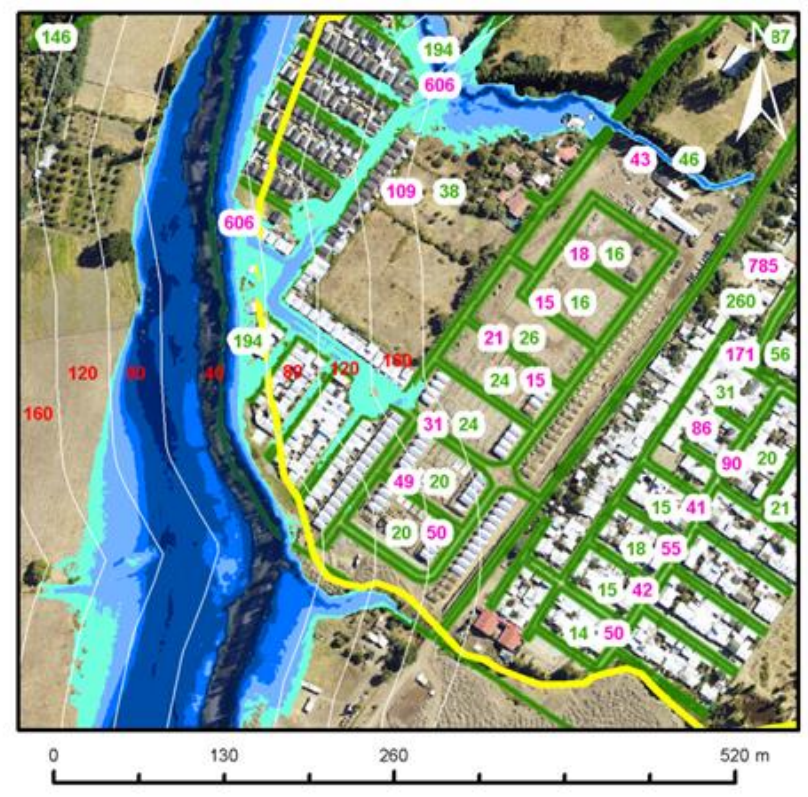

Figura 25a. Fuente: elaboración propia.

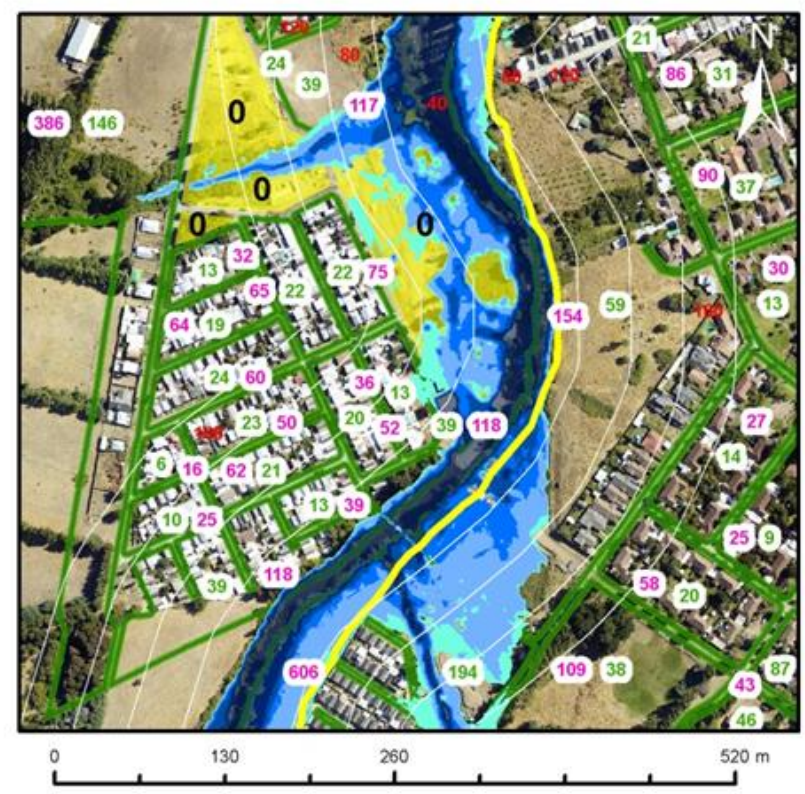

Figura 25b. Fuente: elaboración propia. 


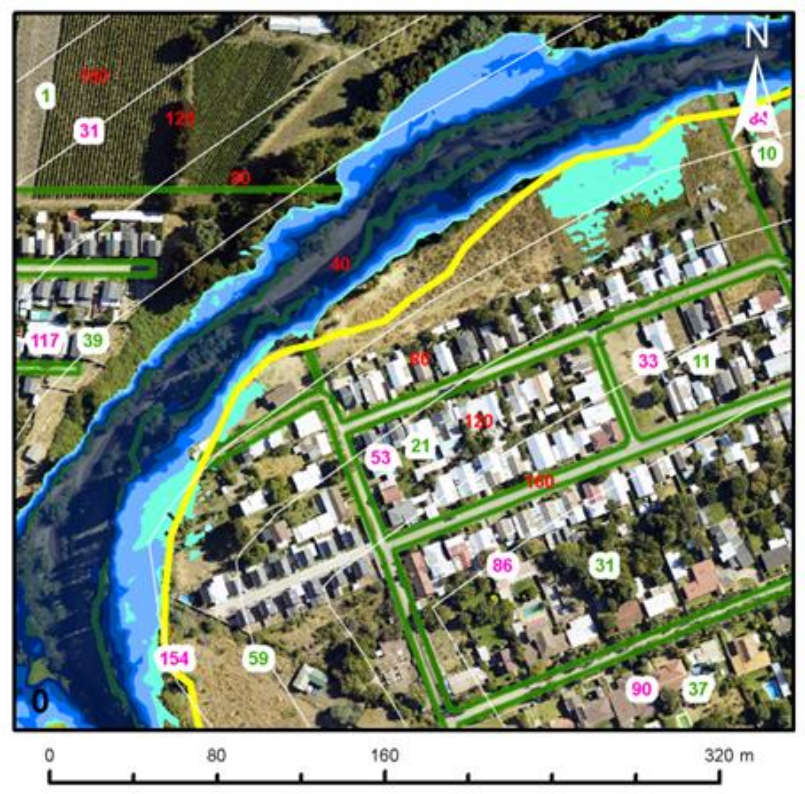

Figura 25c. Fuente: elaboración propia.
Los datos de las manzanas corresponden a información obtenida del CENSO 2017 (IDE Chile) $)^{17}$.

Existen zonas prioritarias en el área de estudio, las cuales fueron determinadas por el MINVU18.

\section{CONCLUSIÓN}

Estudiar y conocer las características del relieve y los elementos sobre este, es esencial para la realización de estudios, $v$. gr. la determinación de las áreas de inundación en zonas urbanas, objetivo del presente proyecto.

Es indudable que la contribución de la tecnología LIDAR en la adquisición de datos de precisión de una gran extensión de terreno, permitió generar MDT y MDS que fue aplicable a gran escala y así obtener resultados confiables y dar cumplimiento al primer objetivo específico que era obtener un modelo lo más representativo del relieve.

Contar con una superficie lo más similar a la realidad trajo consigo beneficios sistemáticos que se traspasaron de fase en fase, permitiendo

\footnotetext{
17 Variable cuantitativa implementada en el SIG.
}

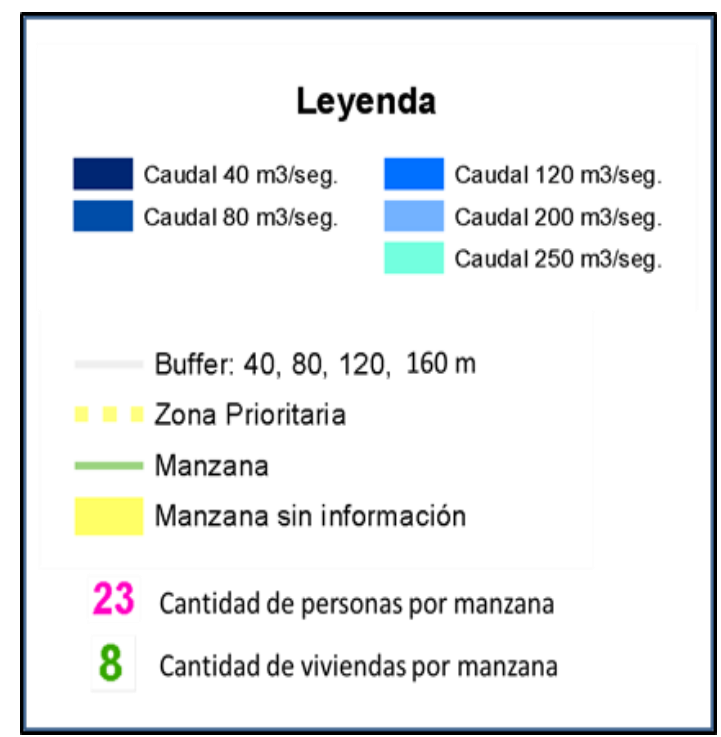

efectuar el modelamiento con datos geométricos del cauce, asistidos por las ortofotos lo más ajustados a la realidad, permitiendo lograr otro objetivo específico que era realizar la modelación y determinar las áreas de inundación sobre un TIN, como también determinar las propiedades topográficas del terreno.

Las áreas de inundación obtenidas le corresponden a los análisis realizados en la integración de los datos al SIG en la última fase y a información obtenida de fuentes gubernamentales, pudiendo de esta manera cumplir con un tercer objetivo específico que era determinar el grado de vulnerabilidad de la población en función de su proximidad al río y áreas de inundación y la densidad de la población en dichas áreas.

En consideración con el producto y alcance descriptivo del estudio, se atiende la relevancia de integrar datos geográficos en distintos sistemas y plataformas con el propósito de obtener información geográfica aplicable que contribuyan al conocimiento de la organización y distribución de la sociedad y fenómenos, y poder subsanar las deficiencias en la planificación urbana por parte de las autoridades.

18 Variable cualitativa auxiliar que puede ser analizada con mayor detalle en otro estudio. 


\section{REFERENCIAS}

Apel, y otros. 2009. 2009.

Aplicaciones de la teledetección láser (LIDAR) en la caracterización y gestión del medio fluvial. Magdaleno Mas, Fernando y Martínez Romero, Roberto. 2006. Madrid : Ingeniería Civil, 2006. ArcGIS for Desktop. ArcMap. [En línea] [Citado el: 19 de Noviembre de 2018.] http://desktop.arcgis.com/es/arcmap/10.3/tools/sp atial-analyst-toolbox/how-stream-order-works.htm. Arellano Sánchez, Javier, Betts Gómez, Sandra y Ramírez Rodríguez, Olivia. s.f.. Gestión de datos LiDAR a través de SIG y base de datos geoespacial. Aguascalientes, México : s.n., s.f.

Chuvieco, Emilio. 1995. Fundamentos de Teledetección Espacial. Madrid: RIALP, S.A., 1995.

Comas, David y Ruiz, Ernert. 1993. Fundamentos de los Sistemas de Información Geográfica. Barcelona : ARIEL S.A., 1993.

Dirección General de Aguas. Ministerio de Obras Públicas. [En línea] [Citado el: 13 de Octubre de 2018.] http://snia.dga.cl/BNAConsultas/reportes.

EducarChile(s.f.). Ríos de Chile. 2018. Hidrogra. [En línea] Octubre de 2018. [Citado el: 29 de Septiembre de 2018.] http://ww2.educarchile.cl/portal.herramientas/nuest ros_sitios/bdrios/sitio/zona4/scuenca5.htm.

Gerl et al. 2016. 2016.

Grupo de Investigación en Transporte de Sedimentos. 2007. Hidrología Básica y Aplicada. Barcelona : s.n., 2007.

Gupiponi et al. 2014. 2014.

IDE Chile. Infra estructura de datos espaciales, Chile. [En línea] [Citado el: 12 de Noviembre de 2018.]

http://www.ide.cl/descarga/capas/item/cartografiacenso-2017-region-de-la-araucania..

INE. Censo de Población y Vivienda 2017. [En línea] [Citado el: 15 de 10 de 2018.] https://redatam-

ine.ine.cl/redbin/RpWebEngine.exe/Portal?BASE= CENSO_2017\&lang=esp.

—. 2017. Censo de Población y Vivienda 2017. [En línea] 2017. [Citado el: 15 de 10 de 2018.] https://redatam-

ine.ine.cl/redbin/RpWebEngine.exe/Portal?BASE= CENSO_2017\&lang=esp.

Ingeniería HIdráulica y Ambiental. 2018. Influencia del método de estimación en el coeficiente de Manning. [En línea] Enero - Abril de 2018. [Citado el: 23 de Noviembre de 2018.]
Lopera Echavarría, Juan, y otros. 2010. Método analítico como método natrual. [En línea] 2010. [Citado el: 11 de Enero de 2019.] https://webs.ucm.es/info/nomadas/25/juandiegolop era.pdf.

MicroStation $\AA$, MDL $\circledast$ y MicroStation estilizados "M", marcas registradas de Bentley Systems. 2016. User's Guide. [aut. libro] Scan y Photo TerraModeler. User's Guide. 2016.

MINVU. 2018. Ley General de Urbanismo y Construcciones. [En línea] 15 de Febrero de 2018. [Citado el: 29 de Septiembre de 2018.] última modificación.

https://www.leychile.cl/Navegar?idNorma $=13560$.

-. Zonas Prioritarias. [En línea] [Citado el: 2 de Diciembre de 2018.] http://www.minvu.cl/opensite_20120720105920.as px.

Paradoja de la Planificación Urbana en Chile. Sabatini, Francisco y Soler, Fernando. 1995. 62, Santiago : s.n., Abril de 1995, Eure, Vol. XXI, pág. 1.

Pinos, Jua, Timbe, Luis y Orellana, Daniel. 2017. Métodos para la evaluación del riesgo de inundación fluvial. Ecuador : MASKANA, 2017.

Sala Sanjaume, María y Batalla Villanueva, Ramón. 1999. Teoría y Métodos en Geografía Física. Madrid : Síntesis S.A., 1999.

Servicio Aerofotogramétrico de la Fuerza Aérea de Chile y Pontifica Universidad Católica de Chile. 2003. Principios y Métodos de la Fotointerpretación. Santiago de Chile : TT.GG. del Servicio Aerofotrogramétricos de la Fuerza Aérea de Chile, 2003.

Strahler, Arthur. 2004. Geología Física. Barcelona : Ediciones OMEGA, 2004.

Strahler, Arthur N. Strahler y Alan H. 1989. Geografía Física. Barcelona: Ediciones OMEGA, 1989.

Subsecretaría de Desarrollo Regional y Administrativo. 2015. [En línea] Junio de 2015. [Citado el: 12 de Noviembre de 2018.]

Universidad de Granada. 2013. Manual Básico de HEC-GeoRAS 10. Granda : s.n., 2013.

Verga Erices, Luis y Rozas Poblete, Mario. 2013. Academia. [En línea] 2013. [Citado el: 24 de Octubre de 2018.] https://www.academia.edu/9385105/Viviendas_So cial_en_la_estructura_urbana_de_Angol_19922012._Chile. 